\title{
Diagnostic accuracy of tests to detect Hepatitis C antibody: a meta-analysis and review of the literature
}

Weiming Tang ${ }^{1,2,3,4^{\dagger}}$, Wen Chen ${ }^{5,6+}$, Ali Amini ${ }^{7}$, Debi Boeras ${ }^{7}$, Jane Falconer ${ }^{7}$, Helen Kelly ${ }^{7}$, Rosanna Peeling ${ }^{7}$, Olivia Varsaneux ${ }^{7}$, Joseph D. Tucker ${ }^{1,3,4,7^{*}}$ and Philippa Easterbrook ${ }^{8}$

\begin{abstract}
Background: Although direct-acting antivirals can achieve sustained virological response rates greater than 90\% in Hepatitis C Virus (HCV) infected persons, at present the majority of HCV-infected individuals remain undiagnosed and therefore untreated. While there are a wide range of HCV serological tests available, there is a lack of formal assessment of their diagnostic performance. We undertook a systematic review and meta-analysis to evaluate he diagnostic accuracy of available rapid diagnostic tests (RDT) and laboratory based EIA assays in detecting antibodies to HCV.
\end{abstract}

Methods: We used the PRISMA checklist and Cochrane guidance to develop our search protocol. The search strategy was registered in PROSPERO (CRD42015023567). The search focused on hepatitis C, diagnostic tests, and diagnostic accuracy within eight databases (MEDLINE, EMBASE, the Cochrane Central Register of Controlled Trials, Science Citation Index Expanded, Conference Proceedings Citation Index-Science, SCOPUS, Literatura Latino-Americana e do Caribe em Ciências da Saúde and WHO Global Index Medicus. Studies were included if they evaluated an assay to determine the sensitivity and specificity of HCV antibody (HCV Ab) in humans. Two reviewers independently extracted data and performed a quality assessment of the studies using the QUADAS tool. We pooled test estimates using the DerSimonian-Laird method, by using the software R and RevMan. 5.3.

Results: A total of 52 studies were identified that included 52,673 unique test measurements. Based on five studies, the pooled sensitivity and specificity of HCV Ab rapid diagnostic tests (RDTs) were 98\% (95\% Cl 98-100\%) and 100\% (95\% Cl 100-100\%) compared to an enzyme immunoassay (EIA) reference standard. High HCV Ab RDTs sensitivity and specificity were observed across screening populations (general population, high risk populations, and hospital patients) using different reference standards (EIA, nucleic acid testing, immunoblot). There were insufficient studies to undertake subanalyses based on HIV co-infection. Oral HCV Ab RDTs also had excellent sensitivity and specificity compared to blood reference tests, respectively at 94\% (95\% Cl 93-96\%) and 100\% (95\% Cl 100-100\%). Among studies that assessed individual oral RDTs, the eight studies revealed that OraQuick ADVANCE ${ }^{\circledast}$ had a slightly higher sensitivity (98\%, 95\% Cl 97-98\%) compared to the other oral brands (pooled sensitivity: 88\%, 95\% Cl 84-92\%).

Conclusions: RDTs, including oral tests, have excellent sensitivity and specificity compared to laboratory-based methods for HCV antibody detection across a wide range of settings. Oral HCV Ab RDTs had good sensitivity and specificity compared to blood reference standards.

Keywords: Diagnostic accuracy, Diagnostic tests, Hepatitis C, HCV antibody, Rapid diagnostic tests

\footnotetext{
*Correspondence: jdtucker@med.unc.edu

${ }^{\dagger}$ Equal contributors

${ }^{1}$ University of North Carolina Project-China, No. 2 Lujing Road, Guangzhou

510095, China

${ }^{3}$ SESH Global, Guangzhou, China

Full list of author information is available at the end of the article
} 


\section{Background}

Hepatitis $C$ is a liver disease caused by the hepatitis $C$ virus $(\mathrm{HCV})$ that causes acute and chronic infection $[1,2]$. An estimated 71 million people had chronic hepatitis $C$ infection worldwide in 2015 [3]. Viral hepatitis caused 1.34 million deaths in 2015, a number comparable to deaths caused by tuberculosis and higher than those caused by HIV [3]. The introduction of direct-acting antivirals (DAAs) has led to a sustained virological response (SVR) in greater than $90 \%$ of treated individuals $[4,5]$. DAAs are now recommended by the World Health Organization (WHO) [1] and many other HCV treatment guidelines [1]. DAAs will not only improve SVR rates but also may simplify HCV management algorithms and allow smaller health facilities to manage HCV-infected individuals [6]. Despite the availability of effective treatment, most $\mathrm{HCV}$-infected individuals remain undiagnosed and untreated [7]. Left untreated, approximately $15-30 \%$ of individuals with chronic $\mathrm{HCV}$ infection progress to cirrhosis, leading to end-stage liver disease and hepatocellular carcinoma $[1,2]$.

In February 2016 the WHO updated the guidelines for the screening, care, and treatment of persons with chronic hepatitis $C$ infection [1]. These guidelines included recommendations on whom to screen for HCV and how to confirm HCV infection, but not which tests are optimal for initial screening. Advances in HCV detection technology create new opportunities for enhancing screening, referral, and treatment. Previous systematic reviews on HCV infection have focused on treatment response $[8,9]$, clinical complications [10], and epidemiology [11, 12]. Two previous systematic reviews on hepatitis $C$ testing have focused on evaluating point-of-care tests compared to EIAs and other reference tests $[13,14]$. We have undertaken a further systematic review and meta-analysis to generate pooled sensitivity and specificity of rapid diagnostic tests used to detect $\mathrm{HCV}$ antibody (HCV Ab), and to inform the development of recommendations on serological testing in the 2017 WHO testing guidelines [15].

\section{Methods}

\section{Research question}

The main purpose of the review was to assess the diagnostic accuracy of available assays for detecting HCV Ab in persons identified for hepatitis $\mathrm{C}$ testing. The research question was structured in a PICO format (ie. population, intervention, comparisons and outcome).

P: Persons identified for $\mathrm{HCV}$ testing; I: Rapid diagnostic tests and enzyme immunoassays for HCV Ab detection; C: 1), EIA (with a subanalysis based on the last 10 years); 2), NAT (nucleic acid testing); 3), Immunoblot or similar assay; 4), A combination of 1,2,3 above; $\mathrm{O}$ : Diagnostic accuracy [Sensitivity (SE), Specificity (SP), Positive predictive value (PPV), Negative predictive value
(NPV), True Negative, True Positive (TP), False negative $(\mathrm{FN})$, and False positive (FP)].

\section{Search strategy and identification of studies}

Search strategies were developed by a medical librarian with expertise in designing systematic review searches. Our search algorithm consisted of the following components: hepatitis $C$, diagnostic tests, and diagnostic accuracy. We searched MEDLINE (OVID interface, 1946 onwards), EMBASE (OVID interface, 1947 onwards), the Cochrane Central Register of Controlled Trials (Wiley interface, current issue), Science Citation Index Expanded (Web of Science interface, 1970 onwards), Conference Proceedings Citation Index-Science (Web of Science interface, 1990 onwards), SCOPUS (1960 onwards), Literatura LatinoAmericana e do Caribe em Ciências da Saúde (LILACS) (BIREME interface) and WHO Global Index Medicus. The search was supplemented by searching for ongoing studies in WHO's International Clinical Trials Registry. The literature search was limited to English language and human subjects that available until April 30th, 2015. In addition to searching databases, we contacted individual researchers and authors of major trials to address whether any relevant manuscripts are in preparation or in press. The references of published articles found in the above databases were searched for additional pertinent materials.

Study selection proceeded in three stages: 1) titles/abstracts were screened by a single reviewer according to standard inclusion and exclusion criteria; 2) full manuscripts were obtained and evaluated by two independent reviewers to include or not; 3) two independent reviewers extracted all data. Differences were resolved by a third independent reviewer.

\section{Selection criteria}

The inclusion criteria included the following: primary purpose was $\mathrm{HCV}$ Ab test evaluation, reported sensitivity and specificity of HCV Ab test kits, and studies published before May 2015. We included observational and randomised control trial (RCT) studies that provided original data from patient specimens. Studies that only reported sensitivity or specificity, conference abstracts, comments or review papers, panel studies, or those that only used reference assays for positive samples were excluded. In this manuscript, a hepatitis panel refers to a laboratory series test in which use the blood with confirmed hepatitis $\mathrm{C}$ serostatus to assess the accuracy of a testing kit.

\section{Data extraction}

Information on the following variables were extracted from each individual study: first author, total sample size, country (and city) of sampling, sample type (oral fluid, finger prick, venous blood), point-of-care (POC, defined as being able to give a result within $60 \mathrm{~min}$ and 
having the results to guide clinical management in the same encounter), eligibility criteria, reference standard, manufacturer, raw cell numbers (true positives, false negatives, false positives, true negatives), antibodyantigen combo (yes or no), sources of funding, reported conflict of interest, and study population (general population, high risk population and hospitalized population). The high risk population groups include men who have sex with men, sex workers and their clients, transgender people, people who inject drugs and prisoners and other incarcerated people [16]. The hospitalized population was defined as those admitted to a hospital for medical care or observation. We also verified whether assays evaluated in the studies were currently on the market (as of June 1st, 2017), and if this was the case, we also reported the available version of the testing kit (Table 1).

\section{Assessment of methodological quality}

Study quality was evaluated using the QUADAS-2 tool [17] and the STARD checklist [18]. QUADAS includes domains to evaluate bias in the following categories: risk of bias (patient selection, index test, reference standard, flow, and timing); applicability concerns (patient selection, index test, reference standard). The STARD checklist consists of a checklist of 25 items and flow diagram that authors can use to ensure that all relevant information is present.

\section{Data analysis and synthesis \\ Data synthesis}

Data were extracted to construct $2 \times 2$ tables. By comparing with reference standard results, the index test results were categorized as a true positive, a false positive, a false negative, or a true negative. Indeterminate test results were not included in pooled analyses.

\section{Statistical analysis}

To estimate test accuracy, we calculated sensitivity and specificity for each study and pooled statistics, along with 95\% confidence intervals [19]. We pooled test estimates using the DerSimonian-Laird method, a bivariate random effect model. We did further subanalyses based on reference standard (EIA alone; NAT or immunoblot; EIA, NAT, or immunoblot), brand, sample type, and combination test. We performed all statistical analysis (including heterogeneity, through Q test) using the software $\mathrm{R}$ and RevMan 5.3 .

\section{Results}

\section{Study selection}

A total of 11,163 citations were identified, and 6163 duplicates were removed. Each of the 5000 unique citations was examined. A total of 52 research studies were included in the final analysis (Fig. 1) [8, 16, 19-68]. Of the 52 studies,
32 studies evaluated the accuracy of 30 different rapid diagnostic tests (RDTs) [19-50], of which 5 evaluated RDTs compared to EIA alone [25, 26, 31, 34, 49], 13 compared RDT results to NAT or immunoblot [19-22, 27, 29, 32, 37, $42,43,45,47,50]$, and 14 focused on evaluating RDT by comparing with the results of EIA or immunoblot or NAT [23-26, 30, 34, 35, 38, 39, 41, 44, 48, 49, 51]. Eleven studies evaluated the diagnostic accuracy of oral fluid RDTs [22, $24,27,29,33,34,43-45,47,52]$.

There were insufficient data to undertake a subanalysis based on HIV co-infection or other co-infections.

\section{Study characteristics}

Of the 52 included studies, nine were published before 2000 [37, 38, 42, 53-58], 12 studies reported evaluation using oral fluid samples, and 34 studies evaluated POC tests. Of the 52 studies, 41 different brands of testing kits were evaluated (Table 1).

\section{Assessment of the quality of the studies}

All studies used a cross-sectional or case-control design. The risk of bias in patient selection, index test, or reference standard was assessed using QUADAS-2 (Table 2). Among the included studies, 25 had at least one category that was considered high risk [19, 22, 25-28, 30, 31, 34, $36-39,41,45-50,53,55,56,58-62]$. The risk of bias in patient selection usually came from a poor description of patient selection and clinical scenario. Bias in the index test was primarily due to a lack of reported blinding while reading test results. Bias in the reference standard was due to the use of multiple reference standards (EIA, NAT, and/or immunoblot). Bias in the flow and timing was primarily due to a lack of reported details.

\section{Diagnostic accuracy}

\section{Overall clinical performance of assays}

The 52 included studies contributed 127 data points from 52,273 unique test measurements. Some studies contributed additional data points by comparing the accuracy of two or more tests, reporting data from multiple study sites, or reporting the accuracy of a test in more than one type of specimen. The sample sizes of the included studies ranged from 37 to 17,894 . Sensitivities of included studies ranged from 22 to $100 \%$, and specificities ranged from 77 to $100 \%$. The overall pooled sensitivity and specificity for all tests were 97\% (95\% CI: 97\%-98\%) and 99\% (95\% CI: 98\%-99\%) respectively. Figure 2 shows estimates of sensitivity and specificity from each study.

\section{Manufacturers and accuracy of RDTs among included studies}

Overall, 32 studies evaluated the accuracy of 30 different RDTs (Table 3 ). The most commonly evaluated test kit was the OraQuick ADVANCE ${ }^{\bullet}$ from OraSure Technologies. 
Table 1 Characteristics of studies focused on evaluating diagnostic accuracy of HCV antibody tests

\begin{tabular}{|c|c|c|c|c|c|c|c|c|c|}
\hline First author & Year & Settings & Sample type & Manufacturer & $\begin{array}{l}\text { Study } \\
\text { type }\end{array}$ & $\begin{array}{l}\text { Sample } \\
\text { size }\end{array}$ & $\begin{array}{l}\mathrm{POC} \\
(\mathrm{Y} / \mathrm{N})\end{array}$ & Reference standard & $\begin{array}{l}\text { Still on the market? } \\
\text { PRODUCT NAME }\end{array}$ \\
\hline Al-Tahish et al. & 2013 & Egypt & $\begin{array}{l}\text { Venous } \\
\text { blood }\end{array}$ & $\begin{array}{l}\text { HCV one step test } \\
\text { device (ACON } \\
\text { Laboratories, USA), } \\
\text { Fourth- generation } \\
\text { HCV TRI_DOT (J. Mitra } \\
\text { Co, India) and } \\
\text { ImmunoComb II HCV } \\
\text { (Inverness Medical } \\
\text { Innovations, USA) }\end{array}$ & CS & 100 & $\bar{Y}$ & $P C R$ & $\begin{array}{l}\text { Yes Foresight }{ }^{\oplus} \mathrm{HCV} \\
\text { EIA test kit; Yes, HCV } \\
\text { TRI_DOT }\end{array}$ \\
\hline Bonacini et al. & 2001 & USA & $\begin{array}{l}\text { Venous } \\
\text { blood }\end{array}$ & $\begin{array}{l}\text { Ortho Clinical } \\
\text { Diagnostics (Raritan, } \\
\text { NJ, USA) }\end{array}$ & CS & 222 & N & $\begin{array}{l}\text { Chiron IMMUNOBLOT } \\
\text { HCV } 3.0 \text { SIA }\end{array}$ & Not available \\
\hline Buti et al. & 2000 & Sprain & Serum & Not available & CS & 188 & Y & IMMUNOBLOT & Not avaliable \\
\hline Caudai et al. & 1998 & USA & $\begin{array}{l}\text { Serum or } \\
\text { plasma } \\
\text { samples }\end{array}$ & $\begin{array}{l}\text { ELISA 2nd generation } \\
\text { Abbott Laboratories, } \\
\text { Abbott park, IL, USA) }\end{array}$ & CS & 682 & N & $P C R$ & Not avaliable \\
\hline Cha et al. & 2013 & Korea & $\begin{array}{l}\text { Oral fluids } \\
\text { and serum }\end{array}$ & $\begin{array}{l}\text { OraQuick (OraSure } \\
\text { Technologies, PA USA) }\end{array}$ & CC & 437 & Y & $P C R$ & $\begin{array}{l}\text { Yes, The OraQuick } \\
\text { HCV }\end{array}$ \\
\hline Croom et al. & 2006 & Austria & $\begin{array}{l}\text { Venous } \\
\text { blood }\end{array}$ & $\begin{array}{l}\text { Monolisa anti-HCV } \\
\text { PLUSVersion } 2 \text { EIA } \\
\text { (Bio-Rad, France) }\end{array}$ & CS & 182 & N & EIA & $\begin{array}{l}\text { Yes, MONOLISA } \\
\text { Anti-HCV PLUS Assay } \\
\text { Version } 2\end{array}$ \\
\hline da Rosa et al. & 2013 & Brazil & Serum & $\begin{array}{l}\text { Rapid Test Bioeasy } \\
\text { (Standard Diagnostics, } \\
\text { Yongin, Korea) and } \\
\text { Imuno-Rapido HCV }{ }^{\circledast} \\
\text { (Wama Diagnostica, } \\
\text { Brazil). }\end{array}$ & CS & 307 & Y & Architect HCV, PCR & $\begin{array}{l}\text { Not available for } \\
\text { Rapid Test Bioeasy; } \\
\text { Yes, Imuno-Rapido } \\
\text { HCV }\end{array}$ \\
\hline Daniel et al. & 2005 & India & Serum & $\begin{array}{l}\text { TRI DOT (J. MITRA \&Co. } \\
\text { Ltd., New Delhi, India) }\end{array}$ & CS & 2590 & Y & $\begin{array}{l}\text { EIA, IMMUNOBLOT, } \\
\text { PCR }\end{array}$ & YES, HCV TRI_DOT \\
\hline Denoyel et al. & 2004 & $\begin{array}{l}\text { France and } \\
\text { Germany }\end{array}$ & $\begin{array}{l}\text { Serum or } \\
\text { plasma } \\
\text { samples }\end{array}$ & $\begin{array}{l}\text { AxSYM HCV } 3.0 \text { (other } \\
\text { information is not } \\
\text { available) }\end{array}$ & CS & 5700 & N & IMMUNOBLOT & Yes, AXSYM HCV 3.0 \\
\hline Dokubo et al. & 2014 & USA & Blood & $\begin{array}{l}\text { HCV Version } 3.0 \text { ELISA } \\
\left(\mathrm{Ortho}^{\oplus}\right)\end{array}$ & CS & 132 & N & $P C R$ & $\begin{array}{l}\text { Yes, ORTHO }{ }^{\oplus} \text { HCV } 3.0 \\
\text { Elisa }\end{array}$ \\
\hline Drobnik et al. & 2011 & USA & Oral fluid & $\begin{array}{l}\text { OraQuick (OraSure } \\
\text { Technologies, PA USA) }\end{array}$ & CS & 484 & Y & EIA, IMMUNOBLOT & $\begin{array}{l}\text { Yes, The OraQuick } \\
\text { HCV }\end{array}$ \\
\hline Eroglu et al. & 2000 & Turkey & $\begin{array}{l}\text { Plasma } \\
\text { specimens }\end{array}$ & ELISA v3.0(Ortho $\left.{ }^{\oplus}\right)$ & CS & 160 & N & $P C R$ & $\begin{array}{l}\text { Yes, ORTHO }{ }^{\circledast} \text { HCV } 3.0 \\
\text { Elisa }\end{array}$ \\
\hline Feucht et al. & 1995 & Germany & $\begin{array}{l}\text { Plasma } \\
\text { specimens }\end{array}$ & $\begin{array}{l}\text { Abbott HCV second- } \\
\text { generation enzyme } \\
\text { immunoassay (other } \\
\text { information is not } \\
\text { available) }\end{array}$ & CS & 262 & N & IMMUNOBLOT & Not avaliable \\
\hline Gao et al. & 2014 & USA & Serum & $\begin{array}{l}\text { OraQuick (OraSure } \\
\text { Technologies, PA USA) }\end{array}$ & $\mathrm{CS}$ & 289 & Y & EIA & $\begin{array}{l}\text { Yes, The OraQuick } \\
\text { HCV }\end{array}$ \\
\hline Hess et al. & 2014 & USA & whole blood & $\begin{array}{l}\text { DPP HIV-HCV-Syphilis } \\
\text { Assay (Chembio Diag- } \\
\text { nostic Systems, Inc., } \\
\text { Medford, NY) }\end{array}$ & CS & 948 & Y & EIA & Not avaliable \\
\hline Hui et al. & 2002 & $\begin{array}{l}\text { Hong kong, } \\
\text { China }\end{array}$ & Whole blood & $\begin{array}{l}\text { OraQuick (OraSure } \\
\text { Technologies, PA USA) }\end{array}$ & $\mathrm{CS}$ & 197 & Y & EIA & $\begin{array}{l}\text { Yes, The OraQuick } \\
\text { HCV }\end{array}$ \\
\hline Ibrahim et al. & 2015 & $\begin{array}{l}\text { Saudi } \\
\text { Arabia }\end{array}$ & Oral fluid & $\begin{array}{l}\text { OraQuick (OraSure } \\
\text { Technologies, PA USA) }\end{array}$ & $\mathrm{CC}$ & 160 & Y & $P C R$ & $\begin{array}{l}\text { Yes, The OraQuick } \\
\text { HCV }\end{array}$ \\
\hline Ivantes et al. & 2010 & Brazil & Whole blood & $\begin{array}{l}\text { HCV Rapid Test } \\
\text { Bioeasy (Bioeasy } \\
\text { Diagnostica Ltda, } \\
\text { Minas Gerais, Brazil) }\end{array}$ & CS & 71 & Y & CLIA & Not available \\
\hline
\end{tabular}


Table 1 Characteristics of studies focused on evaluating diagnostic accuracy of HCV antibody tests (Continued)

\begin{tabular}{|c|c|c|c|c|c|c|c|c|c|}
\hline First author & Year & Settings & Sample type & Manufacturer & $\begin{array}{l}\text { Study } \\
\text { type }\end{array}$ & $\begin{array}{l}\text { Sample } \\
\text { size }\end{array}$ & $\begin{array}{l}\mathrm{POC} \\
(\mathrm{Y} / \mathrm{N})\end{array}$ & Reference standard & $\begin{array}{l}\text { Still on the market? } \\
\text { PRODUCT NAME }\end{array}$ \\
\hline Jewett et al. & 2012 & USA & Oral fluids & $\begin{array}{l}\text { Chembio DPP HCV } \\
\text { test (Chembio } \\
\text { Diagnostic } \\
\text { Systems,USA) and } \\
\text { Rapid HIV/HCV } \\
\text { antibody test } \\
\text { (Medmira Laboratories, } \\
\text { Canada) }\end{array}$ & CS & 407 & $Y$ & IMMUNOBLOT/NAT & $\begin{array}{l}\text { Not available for } \\
\text { Chembio DPP HCV } \\
\text { test; Yes, Multiplo } \\
\text { HBC/HIV/HCV }\end{array}$ \\
\hline Kant et al. & 2012 & Germany & Whole blood & $\begin{array}{l}\text { Toyo anti-HCV test } \\
\text { (Turklab, Izmir, Turkey) }\end{array}$ & CS & 185 & Y & Architect HCV & Yes, anti-HCV TEST \\
\hline Kaur et al. & 2000 & India & Serum & $\begin{array}{l}\text { HCV Bidot (J. Mitra Co., } \\
\text { India) }\end{array}$ & CS & 2754 & Y & EIA 3rd generation & $\begin{array}{l}\text { YES, DIAGNOS HCV } \\
\text { BI-DOT }\end{array}$ \\
\hline Kim et al. & 2013 & $\begin{array}{l}\text { Republic of } \\
\text { Korea }\end{array}$ & Serum & $\begin{array}{l}\text { GENEDIA }{ }^{\oplus} \text { HCV Rapid } \\
\text { LF (Green Cross } \\
\text { medical science corp., } \\
\text { Korea) }\end{array}$ & $\mathrm{CC}$ & 200 & Y & IMMUNOBLOT & $\begin{array}{l}\text { Yes, GENEDIA HCV } \\
\text { Rapid LF test kit }\end{array}$ \\
\hline Kosack et al. & 2014 & Germany & Serum & $\begin{array}{l}\text { The ImmunoFlow HCV } \\
\text { test (Core } \\
\text { Diagnostics,United } \\
\text { Kingdom) }\end{array}$ & CS & 81 & Y & IMMUNOBLOT & $\begin{array}{l}\text { Yes, ImmunoFlow } \\
\mathrm{HCV}\end{array}$ \\
\hline Lakshmi et al. & 2007 & India & Blood & $\begin{array}{l}\text { Beijing United } \\
\text { Biomedical, Ortho } \\
\text { Clinical Diagnostics, } \\
\text { General Biologicals; } \\
\text { other information is } \\
\text { not avaliable }\end{array}$ & CS & 69 & $N$ & $P C R$ & Not avaliable \\
\hline Larrat et al. & 2012 & France & $\begin{array}{l}\text { FSB } \\
\text { (fingerstick } \\
\text { blood) and } \\
\text { oral fluid }\end{array}$ & $\begin{array}{l}\text { CEIA: the Monolisa } \\
\text { HCV-Ag-Ab-ULTRA } \\
\text { (Bio-Rad, Marnes-la- } \\
\text { Coquette, France) }\end{array}$ & CC & 201 & Y & $P C R$ & $\begin{array}{l}\text { Yes, MONOLISA }{ }^{\text {TM }} \text { HCV } \\
\text { Ag-Ab ULTRA }\end{array}$ \\
\hline Lee et al. & 2010 & USA & Oral fluid & $\begin{array}{l}\text { OraQuick (OraSure } \\
\text { Technologies, PA USA) }\end{array}$ & $\mathrm{CS}$ & 572 & Y & EIA, IMMUNOBLOT & $\begin{array}{l}\text { Yes, The OraQuick } \\
\text { HCV }\end{array}$ \\
\hline Lee et al. & 2011 & USA & $\begin{array}{l}\text { Serum, } \\
\text { plasma, } \\
\text { venous } \\
\text { blood, } \\
\text { figerstick } \\
\text { blood and } \\
\text { oral fluid }\end{array}$ & $\begin{array}{l}\text { Or Quick (OraSure } \\
\text { Technologies, PA USA) }\end{array}$ & CS & 2183 & Y & $\begin{array}{l}\text { EIA, IMMUNOBLOT, } \\
\text { PCR }\end{array}$ & $\begin{array}{l}\text { Yes, The OraQuick } \\
\text { HCV }\end{array}$ \\
\hline Lee et al. & 2011 & USA & Oral fluid & $\begin{array}{l}\text { OraQuick (OraSure } \\
\text { Technologies, PA USA) }\end{array}$ & CS & $\begin{array}{l}2180 \\
2178\end{array}$ & Y & EIA & $\begin{array}{l}\text { Yes, The OraQuick } \\
\text { HCV }\end{array}$ \\
\hline Maity et al. & 2012 & India & Serum & $\begin{array}{l}\text { J Mitra \& Co. Pvt. Ltd., } \\
\text { SPAN Diagnostics Ltd. } \\
\text { and Standard } \\
\text { Diagnostics, INC, other } \\
\text { information is not } \\
\text { available }\end{array}$ & $\mathrm{CC}$ & 100 & Y & EIA & Not avaliable \\
\hline $\begin{array}{l}\text { Montebugnoil } \\
\text { et al. }\end{array}$ & 1999 & Italy & whole blood & $\begin{array}{l}\text { Anti-HCV Ab rapid test } \\
\text { (1st IRP } 75 / 537 \text { by } \\
\text { Thema Ricerca, WHO } \\
\text { Geneva) }\end{array}$ & $\mathrm{CC}$ & 100 & Y & EIA, IMMUNOBLOT & Not avaliable \\
\hline Mvere et al. & 1996 & Zimbabwe & Serum & $\begin{array}{l}\text { HCV-SPOT (Genelabs } \\
\text { Diagnostics, } \\
\text { Singapore) }\end{array}$ & CS & 206 & Y & $\begin{array}{l}\text { EIA 2nd generation, } \\
\text { INNO-LIA HCV ab III }\end{array}$ & Not avaliable \\
\hline Nalpas et al. & 1992 & France & Serum & $\begin{array}{l}\text { Ortho Diagnostics, } \\
\text { other information is } \\
\text { not available }\end{array}$ & CS & 62 & $\mathrm{~N}$ & $P C R$ & Not avaliable \\
\hline Njouom et al. & 2006 & Cameroon & Plasma & $\begin{array}{l}\text { ImmunoComb }{ }^{\circledast} \text { || HCV } \\
\text { assay (Orgenics Ltd.); }\end{array}$ & CS & 329 & Y & $\begin{array}{l}\text { EIA 3rd generation, } \\
\text { PCR }\end{array}$ & Not avaliable \\
\hline
\end{tabular}


Table 1 Characteristics of studies focused on evaluating diagnostic accuracy of HCV antibody tests (Continued)

\begin{tabular}{|c|c|c|c|c|c|c|c|c|c|}
\hline First author & Year & Settings & Sample type & Manufacturer & $\begin{array}{l}\text { Study } \\
\text { type }\end{array}$ & $\begin{array}{l}\text { Sample } \\
\text { size }\end{array}$ & $\begin{array}{l}\mathrm{POC} \\
(\mathrm{Y} / \mathrm{N})\end{array}$ & Reference standard & $\begin{array}{l}\text { Still on the market? } \\
\text { PRODUCT NAME }\end{array}$ \\
\hline & & & & $\begin{array}{l}\text { ImmunoComb }{ }^{\oplus} \| \mathrm{HCV} \\
\text { assay (Orgenics Ltd., } \\
\text { Not reported } \\
\text { manufacturer located } \\
\text { country) }\end{array}$ & & & & & \\
\hline Nyirenda et al. & 2008 & Malawi & Serum & $\begin{array}{l}\text { Monoelisa HCV Ag/Ab } \\
\text { ultra-microplate EIA } \\
\text { (Bio-Rad, France) }\end{array}$ & CS & 202 & Y & EIA & $\begin{array}{l}\text { Yes, MONOLISA }{ }^{\text {TM }} \text { HCV } \\
\text { Ag-Ab ULTRA }\end{array}$ \\
\hline $\begin{array}{l}\text { O'Connell } \\
\text { et al. }\end{array}$ & 2013 & USA & $\begin{array}{l}\text { Plasma, } \\
\text { whole blood } \\
\text { (normal) and } \\
\text { whole blood } \\
\text { (cold storge) }\end{array}$ & $\begin{array}{l}\text { OraQuick (OraSure } \\
\text { Technologies, PA USA); } \\
\text { CORE (CORE } \\
\text { Diagnostics, United } \\
\text { Kingdom); Axiom } \\
\text { (Axiom Diagnostics, } \\
\text { Burstadt,Germany); } \\
\text { FirstVue (AT First } \\
\text { Diagnostic, } \\
\text { Woodbury,NY, USA) } \\
\text { and Instant View } \\
\text { Cassette (Alfa Scientific } \\
\text { Designs, Poway) }\end{array}$ & CC & $\begin{array}{l}674 \\
168\end{array}$ & Y & $\begin{array}{l}\text { EIA, IMMUNOBLOT, } \\
\text { and when available } \\
\text { viral load) }\end{array}$ & $\begin{array}{l}\text { Yes, The OraQuick } \\
\text { HCV; Yes, Core HCV; } \\
\text { Not avaliable for } \\
\text { Axiom; Yes, FirstVue'TM } \\
\text { Hepatitis "C" Rapid } \\
\text { Test; Yes, Instant- } \\
\text { view" }{ }^{\text {TM }} \text { Hepatitis C } \\
\text { Virus (HCV) Serum } \\
\text { Test }\end{array}$ \\
\hline O'Flynn et al. & 1997 & $\begin{array}{l}\text { Ireland, } \\
\text { Germany, } \\
\text { UK }\end{array}$ & $\begin{array}{l}\text { Plasma and } \\
\text { serum }\end{array}$ & $\begin{array}{l}\text { AxSYM (Abbott } \\
\text { Laboratories, other } \\
\text { information is not } \\
\text { available) }\end{array}$ & $\mathrm{CC}$ & $\begin{array}{l}5554 \\
1421 \\
643\end{array}$ & $N$ & $\begin{array}{l}\text { ABBOTT MATRIX HCV, } \\
\text { Chiron IMMUNOBLOT } \\
\text { HCV } 2.0 \text { or } 3.0\end{array}$ & Yes, AXSYM HCV 3.0 \\
\hline Park et al. & 2012 & Korea & Serum & $\begin{array}{l}\text { Vitros anti-HCV assay } \\
\text { kits (Ortho-Clinical } \\
\text { Diagnostics, Bucking- } \\
\text { hamshire, UK) and } \\
\text { Elecsys (Roche Diag- } \\
\text { nostics GmbHMann- } \\
\text { heim, Germany) }\end{array}$ & CS & 1008 & $N$ & $\begin{array}{l}\text { IMMUNOBLOT HCV } 3.0 \\
\text { and Cobas Ampliprep/ } \\
\text { Taqman HCV RNA }\end{array}$ & Not avaliable \\
\hline $\begin{array}{l}\text { Poovorawari } \\
\text { et al. }\end{array}$ & 1994 & Thailand & Serum & $\begin{array}{l}\text { HCV-SPOT assay } \\
\text { (Genelabs Diagnostics } \\
\text { Pty Ltd., Singapore) }\end{array}$ & CS & 192 & Y & $\begin{array}{l}\text { EIA 2nd generation or } \\
\text { IMMUNOBLOT }\end{array}$ & Not avaliable \\
\hline Prayson et al. & 1993 & USA & Serum & $\begin{array}{l}\text { C100-3 HCV EIA } \\
\text { (Abbott Laboratories, } \\
\text { other information is } \\
\text { not available) }\end{array}$ & CS & 123 & $N$ & IMMUNOBLOT 2.0 & Not avaliable \\
\hline Rihn et al. & 2000 & France & serum & $\begin{array}{l}\text { MATRIX hcv2 (Abbott } \\
\text { Laboratories, other } \\
\text { information is not } \\
\text { available) }\end{array}$ & CS & 146 & $N$ & $P C R$ & Not avaliable \\
\hline $\begin{array}{l}\text { Scalioni Lde } \\
\text { et al. }\end{array}$ & 2014 & Brazil & $\begin{array}{l}\text { Serum, whole } \\
\text { blood and } \\
\text { oral fluid }\end{array}$ & $\begin{array}{l}\text { WAMA Imuno-Rápido } \\
\text { HCV Kit (WAMA Diag- } \\
\text { nóstica, Brazil); Bioeasy } \\
\text { HCV Rapid Test, } \\
\text { (Bioeasy Diagnóstica } \\
\text { Ltd., Brazil) and Ora- } \\
\text { Quick (OraSure Tech- } \\
\text { nologies, PA USA) }\end{array}$ & CS & $\begin{array}{l}194 \text { or } \\
172\end{array}$ & Y & $P C R$ & $\begin{array}{l}\text { Yes, Imuno-Rapido } \\
\text { HCV; Not avaliable for } \\
\text { Rapid Test Bioeasy; } \\
\text { Yes, The OraQuick } \\
\text { HCV }\end{array}$ \\
\hline Smith et al. & 2011 & USA & $\begin{array}{l}\text { Whole blood, } \\
\text { oral fluid }\end{array}$ & $\begin{array}{l}\text { Multiplo Rapid HIV/ } \\
\text { HCV Antibody Test } \\
\text { (MedMira, Canada); } \\
\text { Chembio DPP HCV } \\
\text { test (Chembio } \\
\text { Diagnostic Systems, } \\
\text { USA) and OraQuick } \\
\text { (OraSure Technologies, } \\
\text { USA) }\end{array}$ & CS & $\begin{array}{l}476 \\
385 \\
432 \\
549 \\
266\end{array}$ & Y & $\begin{array}{l}\text { MEIA/EIA/CLIA, } \\
\text { IMMUNOBLOT }\end{array}$ & $\begin{array}{l}\text { Yes, Multiplo HBc/HIV/ } \\
\text { HCV; Not avaliable for } \\
\text { Chembio DPP HCV } \\
\text { test; Yes, The } \\
\text { OraQuick }{ }^{\oplus} \text { HCV }\end{array}$ \\
\hline Smith et al. & 2011 & USA & $\begin{array}{l}\text { Oral fluid and } \\
\text { blood }\end{array}$ & $\begin{array}{l}\text { Multiplo Rapid HIV/ } \\
\text { HCV Antibody Test }\end{array}$ & CS & 1081 & Y & $\begin{array}{l}\text { Chiron IMMUNOBLOT } \\
\text { HCV } 3.0 \text { SIA; Bayer }\end{array}$ & $\begin{array}{l}\text { Yes, Multiplo HBc/HIV/ } \\
\text { HCV; Not avaliable for }\end{array}$ \\
\hline
\end{tabular}


Table 1 Characteristics of studies focused on evaluating diagnostic accuracy of HCV antibody tests (Continued)

\begin{tabular}{|c|c|c|c|c|c|c|c|c|c|}
\hline First author & Year & Settings & Sample type & Manufacturer & $\begin{array}{l}\text { Study } \\
\text { type }\end{array}$ & $\begin{array}{l}\text { Sample } \\
\text { size }\end{array}$ & $\begin{array}{l}\mathrm{POC} \\
(\mathrm{Y} / \mathrm{N})\end{array}$ & Reference standard & $\begin{array}{l}\text { Still on the market? } \\
\text { PRODUCT NAME }\end{array}$ \\
\hline & & & & $\begin{array}{l}\text { (MedMira, Canada); } \\
\text { Chembio DPP HCV } \\
\text { test (Chembio } \\
\text { Diagnostic Systems, } \\
\text { USA) }\end{array}$ & & & & $\begin{array}{l}\text { Advia Centaur HCV } \\
\text { Chemiluminescent } \\
\text { immunoassay }\end{array}$ & $\begin{array}{l}\text { Chembio DPP HCV } \\
\text { test }\end{array}$ \\
\hline $\begin{array}{l}\text { Sommese } \\
\text { et al. }\end{array}$ & 2014 & Italy & Blood & $\begin{array}{l}\text { CMIA assays (Abbott } \\
\text { Diagnostics, } \\
\text { Wiesbaden, Germany) }\end{array}$ & CS & 17,894 & N & $\begin{array}{l}\text { INNO-LIA } \\
\text { (Innogenetics, Ghent, } \\
\text { Belgium), NAT }\end{array}$ & Not avaliable \\
\hline Tagny et al. & 2014 & Cameron & Plasma & $\begin{array}{l}\text { HCV Ag/Ab } \\
\text { combination assay } \\
\text { (Monolisa HCV Ag-Ab } \\
\text { Ultra, BioRad, Marnes } \\
\text { La Coquette, France) }\end{array}$ & CS & 1998 & Y & EIA & $\begin{array}{l}\text { Yes, MONOLISA }{ }^{\mathrm{TM}} \mathrm{HCV} \\
\text { Ag-Ab ULTRA }\end{array}$ \\
\hline Vrielink et al. & 1996 & Netherlands & Blood & $\begin{array}{l}\text { Abbott HCV EIA } 3.0 \\
\text { (Abbott laboratories, } \\
\text { Murex anti-HCV VK47 } \\
\text { (Murex Diagnostic) } \\
\text { and Ortho HCV } 3.0 \\
\text { elisa (Ortho Diagnostic } \\
\text { Systems; other infor- } \\
\text { mation is not available }\end{array}$ & CS & $\begin{array}{l}403 \\
212 \\
25303 \\
1055\end{array}$ & N & $P C R$ & $\begin{array}{l}\text { Not available for } \\
\text { Abbott HCV EIA 3.0; } \\
\text { Yes, Murex anti-HCV } \\
\text { (version 4); Yes, OR- } \\
\text { THO }{ }^{\circledR} \text { HCV } 3.0 \text { Elisa }\end{array}$ \\
\hline Vrielink et al. & 1995 & Netherlands & Blood & $\begin{array}{l}\text { Monolisa anti-HCV } \\
\text { new antigens (Sanofi } \\
\text { Diagnostics Pasteur), } \\
\text { Abbott HCV EIA 3.0 } \\
\text { (Abbott Laboratories); } \\
\text { other information is } \\
\text { not available }\end{array}$ & CS & $\begin{array}{l}403 \\
212 \\
253\end{array}$ & $\mathrm{~N}$ & $P C R$ & Not avaliable \\
\hline Yang et al. & 2011 & China & Serum & $\begin{array}{l}\text { AxSYM HCV } 3.0 \\
\text { (Abbott Laboratories), } \\
\text { Murex Ag/Ab test } \\
\text { (Abbott Laboratories); } \\
\text { other information is } \\
\text { not available }\end{array}$ & $\mathrm{CC}$ & $\begin{array}{l}101 \text { or } \\
100\end{array}$ & N & $\begin{array}{l}\text { HCV RNA test (COBAS } \\
\text { AMPLICOR Hepatitis C } \\
\text { Virus Test, version } 2.0\end{array}$ & $\begin{array}{l}\text { Yes, AXSYM HCV 3.0; } \\
\text { Not avaliable for } \\
\text { Murex Ag/Ab test }\end{array}$ \\
\hline Yang et al. & 2013 & China & Serum & $\begin{array}{l}\text { Elecsys anti-HCV ॥ } \\
\text { (Roche Diagnostics } \\
\text { GmbH), Architect anti- } \\
\text { HCV (Abbott) and } \\
\text { Vitros anti-HCV (Ortho- } \\
\text { Clinical Diagnostics), } \\
\text { other information is } \\
\text { not available }\end{array}$ & CS & $\begin{array}{l}859 \text { or } \\
167\end{array}$ & $\mathrm{~N}$ & $\begin{array}{l}\text { IMMUNOBLOT } 3.0 \text { test } \\
\text { or the Realtime HCV } \\
\text { RNA assay }\end{array}$ & $\begin{array}{l}\text { Yes, Elecsys }{ }^{\circledast} \text { Anti-HCV } \\
\text { II; Yes, ARCHITECT } \\
\text { i1000SR I; Not avail- } \\
\text { able for Ortho-Clinical } \\
\text { Diagnostics }\end{array}$ \\
\hline Yarri et al. & 2006 & Israel & $\begin{array}{l}\text { Serum and } \\
\text { oral fluid }\end{array}$ & $\begin{array}{l}\text { ImmunoComb || HCV } \\
\text { (Inverness Medical } \\
\text { Innovations, USA) }\end{array}$ & CS & 37 & Y & $P C R$ & Not avaliable \\
\hline Yoo et al. & 2015 & $\begin{array}{l}\text { South } \\
\text { Korea; } \\
\text { China; } \\
\text { China/ } \\
\text { Taiwan; } \\
\text { Thailand; } \\
\text { Australia; } \\
\text { Malaysia; } \\
\text { Indonesia }\end{array}$ & Serum & $\begin{array}{l}\text { Elecsys }{ }^{\oplus} \text { Anti-HCV II } \\
\text { assay; (Roche Diagnos- } \\
\text { tics GmbH, other infor- } \\
\text { mation is not } \\
\text { avaliable) }\end{array}$ & CS & 7726 & Y & 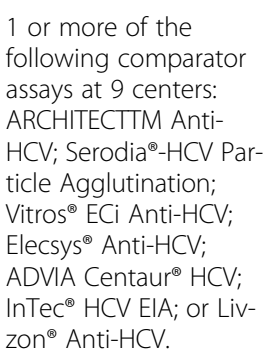 & $\begin{array}{l}\text { Yes, Elecsys }{ }^{\circledast} \text { Anti-HCV } \\
\|\end{array}$ \\
\hline Yuen et al. & 2001 & China & Serum & $\begin{array}{l}\text { SM-HCV Rapid Test } \\
\text { (SERO-Med } \\
\text { Laborspezialita"ten } \\
\text { GmbH, Eichsta "tt, } \\
\text { Germany) }\end{array}$ & $\mathrm{CC}$ & 290 & Y & EIA, PCR & Not avaliable \\
\hline
\end{tabular}




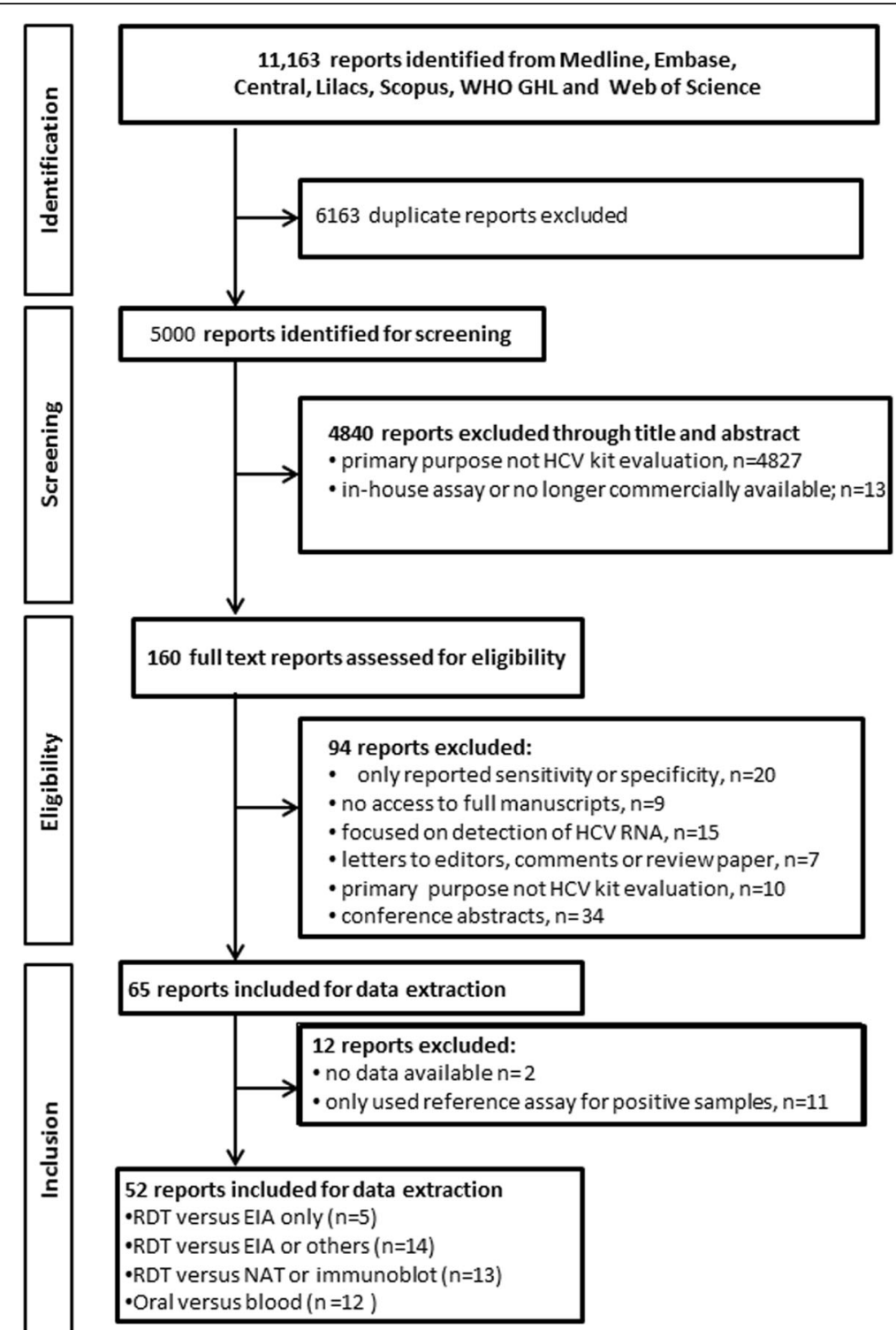

Fig. 1 PRISMA flow diagram outlining study selection examining the diagnostic accuracy of HCV antibody tests

\section{Pooled test accuracy for RDT versus EIA alone}

Overall, five studies evaluated RDTs compared to the EIA alone, with a total sample of 15,943 . Of the five studies, sample sizes ranged from 197 to 2754, sensitivities ranged from 83 to $100 \%$, and specificities ranged from 99 to $100 \%$. The pooled sensitivity and specificity were 98\% (95\% CI 98\%-100\%) and 100\% (95\% CI 100\%-100\%), respectively, while heterogeneity was observed in the included studies $(P<0.001)$ (Table 3, Additional file 1).

For the three studies that were conducted within the last 10 years $[25,49,51]$, the total sample size was 12,992, with pooled sensitivity and specificity of 99\% (95\%CI 99\%-100\%) and $100 \%$ (95\%CI 100\%$100 \%)$, respectively.

\section{RDT accuracy compared to NAT or immunoblot}

Overall, 13 studies evaluated RDTs compared to NAT or immunoblot [19-22, 27, 29, 32, 37, 42, 43, 45, 47, 50], with a total sample of 7083. Among these studies, sample sizes ranged from 36 to 549, sensitivities ranged from 76 to $100 \%$, and specificities ranged from $77 \%$ to $100 \%$. The pooled sensitivity and specificity were 93\% (95\% CI 91\%-95\%) and 98\% (95\% CI 98\%- 99\%), respectively, while heterogeneity was observed in the included studies $(P<0.001)$ (Table 3, Additional file 2).

\section{RDT test accuracy compared to EIA, NAT or Immunoblot}

Overall, 14 studies evaluated RDTs by referencing to EIA with NAT and/or immunoblot [25, 26, 31, 33-35, $38,39,41,45,48,49]$, with a total sample of 42,212 . Of 
Table 2 Quality assessment by QUADAS-2 of the included studies

\begin{tabular}{|c|c|c|c|c|c|c|c|c|}
\hline \multirow[t]{2}{*}{ Reports } & & \multicolumn{4}{|c|}{ Bias assessment/Risk of bias } & \multicolumn{3}{|c|}{ Acceptability concerns } \\
\hline & & Patient selection & Index test & Reference Standard & Flow and timing & Patient selection & Index test & Reference Standard \\
\hline Al-Tahish et al. & 2013 & UC & LR & LR & LR & $L R$ & LR & $L R$ \\
\hline Bonacini et al. & 2001 & $H R$ & $L R$ & $L R$ & $L R$ & $L R$ & $L R$ & $L R$ \\
\hline Buti et al. & 2000 & UC & UC & $L R$ & LR & $\mathrm{HR}$ & LR & $L R$ \\
\hline Caudai et al. & 1998 & $H R$ & $L R$ & $L R$ & $L R$ & $U C$ & $L R$ & $L R$ \\
\hline Cha et al. & 2013 & $H R$ & $L R$ & $L R$ & $L R$ & UC & $L R$ & $L R$ \\
\hline Croom et al. & 2006 & $L R$ & $L R$ & $L R$ & UC & $L R$ & $L R$ & $L R$ \\
\hline da Rosa et al. & 2013 & $\mathrm{HR}$ & UC & $L R$ & $L R$ & $\mathrm{HR}$ & UC & $L R$ \\
\hline Daniel et al. & 2005 & $L R$ & $L R$ & $L R$ & $L R$ & $L R$ & $L R$ & $L R$ \\
\hline Denoyel et al. & 2004 & UC & $L R$ & $L R$ & $L R$ & UC & LR & $\mathrm{HR}$ \\
\hline Drobnik et al. & 2011 & $L R$ & UC & $L R$ & UC & $L R$ & UC & $L R$ \\
\hline Eroglu et al. & 2000 & LR & $L R$ & $L R$ & $L R$ & $L R$ & LR & $L R$ \\
\hline Feucht et al. & 1995 & $H R$ & $L R$ & $L R$ & $L R$ & $H R$ & $L R$ & $L R$ \\
\hline Gao et al. & 2014 & $L R$ & $L R$ & $L R$ & $\mathrm{HR}$ & $L R$ & $L R$ & $L R$ \\
\hline Hess et al. & 2014 & $L R$ & $H R$ & $L R$ & $L R$ & $L R$ & $H R$ & $L R$ \\
\hline Hui et al. & 2002 & $\mathrm{HR}$ & $L R$ & $\mathrm{HR}$ & $L R$ & $\mathrm{HR}$ & $L R$ & $\mathrm{HR}$ \\
\hline Ivantes et al. & 2010 & $L R$ & UC & $H R$ & $L R$ & $L R$ & $L R$ & $H R$ \\
\hline Jewett et al. & 2012 & $L R$ & $L R$ & $L R$ & $L R$ & $L R$ & $L R$ & $L R$ \\
\hline Dokuboa et al. & 2014 & UC & $L R$ & $L R$ & $L R$ & UC & $L R$ & $L R$ \\
\hline Kant et al. & 2012 & $H R$ & UC & $H R$ & $L R$ & $\mathrm{HR}$ & UC & $H R$ \\
\hline Kaur et al. & 2000 & $L R$ & UC & $H R$ & $L R$ & $L R$ & $\mathrm{LR}$ & $L R$ \\
\hline Kim et al. & 2013 & UC & $L R$ & $L R$ & $L R$ & $U C$ & $L R$ & $L R$ \\
\hline Kosack et al. & 2014 & $H R$ & $L R$ & $L R$ & $L R$ & $H R$ & $L R$ & $L R$ \\
\hline Lakshmi et al. & 2007 & UC & $L R$ & $L R$ & UC & $\mathrm{HR}$ & $L R$ & $L R$ \\
\hline Larrat et al. & 2012 & $L R$ & $L R$ & $L R$ & $L R$ & $L R$ & $L R$ & $L R$ \\
\hline Lee et al. & 2010 & $L R$ & UC & $L R$ & $L R$ & $L R$ & UC & $L R$ \\
\hline Lee et al. & 2011 & $H R$ & UC & $L R$ & $L R$ & $L R$ & LR & $L R$ \\
\hline Maity et al. & 2012 & $H R$ & UC & $H R$ & $L R$ & $H R$ & UC & $H R$ \\
\hline Montebugnoil et al. & 1999 & $\mathrm{HR}$ & LR & $L R$ & $L R$ & $\mathrm{HR}$ & LR & $L R$ \\
\hline Mvere et al. & 1996 & $\mathrm{HR}$ & $L R$ & $L R$ & $L R$ & $H R$ & $L R$ & $L R$ \\
\hline Nalpas et al. & 1992 & $H R$ & $L R$ & $L R$ & UC & $\mathrm{HR}$ & $L R$ & $L R$ \\
\hline Njouom et al. & 2006 & $H R$ & UC & $L R$ & $L R$ & $H R$ & UC & $L R$ \\
\hline Nyirenda et al. & 2008 & $L R$ & UC & $L R$ & $L R$ & $L R$ & $L R$ & $L R$ \\
\hline O'Connell et al. & 2013 & $H R$ & $L R$ & $H R$ & $L R$ & $H R$ & $L R$ & $L R$ \\
\hline O'Flynn et al. & 1997 & UC & $L R$ & $L R$ & UC & $L R$ & $L R$ & $L R$ \\
\hline Park et al. & 2012 & UC & $L R$ & $L R$ & UC & $L R$ & $L R$ & $L R$ \\
\hline Poovorawari et al. & 1994 & $L R$ & UC & $L R$ & $L R$ & $L R$ & $L R$ & $L R$ \\
\hline Prayson et al. & 1993 & UC & $L R$ & $L R$ & UC & $U C$ & $L R$ & $L R$ \\
\hline Rihn et al. & 2000 & UC & $L R$ & $L R$ & UC & $U C$ & $L R$ & $L R$ \\
\hline Scalioni et al. & 2014 & UC & $L R$ & $L R$ & UC & UC & $L R$ & $L R$ \\
\hline Smith et al. & 2011 & $L R$ & $L R$ & $L R$ & $L R$ & $L R$ & $L R$ & $L R$ \\
\hline Smith et al. & 2011 & $H R$ & $L R$ & $L R$ & $L R$ & $\mathrm{HR}$ & $\mathrm{LR}$ & $L R$ \\
\hline Sommese et al. & 2014 & $L R$ & $L R$ & $L R$ & $L R$ & $L R$ & $L R$ & $L R$ \\
\hline Lee et al. & 2010_2 & $L R$ & $L R$ & $L R$ & LR & LR & $\mathrm{LR}$ & $L R$ \\
\hline
\end{tabular}


Table 2 Quality assessment by QUADAS-2 of the included studies (Continued)

\begin{tabular}{|c|c|c|c|c|c|c|c|c|}
\hline \multirow[t]{2}{*}{ Reports } & & \multicolumn{4}{|c|}{ Bias assessment/Risk of bias } & \multicolumn{3}{|c|}{ Acceptability concerns } \\
\hline & & Patient selection & Index test & Reference Standard & Flow and timing & Patient selection & Index test & Reference Standaro \\
\hline Ibrahim et al. & 2015 & $\mathrm{HR}$ & LR & $L R$ & LR & $\mathrm{HR}$ & LR & LR \\
\hline Tagny et al. & 2014 & $L R$ & UC & $H R$ & $L R$ & $L R$ & UC & $H R$ \\
\hline Vrielink et al. & 1995 & UC & $L R$ & $L R$ & LR & UC & LR & $L R$ \\
\hline Vrielink et al. & 1995_2 & UC & $L R$ & $L R$ & LR & $H R$ & LR & $L R$ \\
\hline Yang et al. & 2011 & UC & $L R$ & LR & LR & UC & LR & $L R$ \\
\hline Yang et al. & 2013 & LR & $L R$ & LR & UC & $L R$ & $L R$ & $L R$ \\
\hline Yarri et al. & 2006 & $H R$ & $L R$ & $L R$ & LR & $\mathrm{HR}$ & $L R$ & $L R$ \\
\hline Yoo & 2015 & UC & $L R$ & LR & $\mathrm{HR}$ & UC & LR & $L R$ \\
\hline Yuen et al. & 2001 & $H R$ & LR & $L R$ & $L R$ & $H R$ & LR & $L R$ \\
\hline
\end{tabular}

$\mathrm{N}$;otes: $L R$ low risk, $H R$ high risk, UC unclear risk

the 14 studies, sample sizes ranged from 168 to 2754, sensitivities ranged from 29 to $100 \%$, and specificities ranged from 90 to $100 \%$. The pooled sensitivity and specificity were $97 \%$ (95\% CI 96\% -98\%) and 100\% (95\% CI 100\%-100\%), respectively, while heterogeneity was observed in the included studies $(P<0.001)$ (Table 3 , Additional file 3).

\section{Pooled test accuracy for oral versus blood samples EIAs using oral fluid samples}

Overall, 11 studies compared the accuracy of EIAs using oral fluid samples to a blood sample as a reference, with a total sample size of 12,370 [22, 24, 27, 29, 33, 34, 43$45,47,52]$. Of the 12 studies, sample sizes ranged from 37 to 2176 , sensitivities ranged from 72 to $100 \%$, and specificities ranged from 91 to $100 \%$. The pooled sensitivity and specificity were $94 \%$ (95\% CI 93\%-96\%) and 100\% (95\% CI 99\%-100\%), respectively. Heterogeneity was observed in the included studies $(P<0.001)$ (Table 3 , Additional file 4).

\section{Blood samples}

Overall, 47 studies used blood samples for evaluations, with a total sample of 90,008 . Sample sizes ranged from 37 to 17,894 , sensitivities ranged from 29 to $100 \%$, and specificities ranged from 18 to $100 \%$. The pooled sensitivity and specificity were 98\% (95\% CI 97\%-98\%) and 98\% (95\% CI 98\%-98\%), respectively. Heterogeneity was observed in the included studies $(P<0.001)$ (Table 3, Fig. 3).

\section{Pooled test accuracy for OraQuick versus other brands on oral kits \\ OraQuick}

Overall, eight studies reported sensitivity and specificity of OraQuick (OraSure Technologies, PA, USA), with a total sample of 9024 [22, 24, 27, 33-35, 43, 45]. The sample size of these studies ranged from 172 to 2183 , sensitivities ranged from $90 \%$ to $100 \%$, and specificities ranged from $95 \%$ to $100 \%$. The pooled sensitivity and specificity were 98\% (95\% CI 97\%-99\%) and 100\% (95\% CI 90\%-100\%), respectively. Heterogeneity was observed in the included studies $(P<0.001)$ (Table 3 , Additional file 5).

Overall, six studies reported sensitivity and specificity for other three brands of oral kits [29, 43-45, 47, 52], with a total sample of 6652 . The sample size of these studies ranged from 37 to 1081, sensitivities ranged from 72 to $100 \%$, and specificities ranged from 91 to $100 \%$. The pooled sensitivity and specificity were $88 \%$ (95\% CI 84\%-92\%) and 99\% (95\% CI 99\%-100\%), respectively, while heterogeneity was observed between the included studies $(P<0.001)$ (Table 3, Additional file 6).

\section{Other findings}

Our study further found that the overall sensitivity and specificity of studies conducted among general populations were 95\% (95\% CI 94\%-96\%) and 99\% (95\% CI 98\%-99\%), among high risk populations were 97\% (95\% CI 96\%-98\%) and 94\% (95\% CI 94\%-95\%), and among hospital patients were 97\% (95\% CI 96\%98\%) and $100 \%$ (95\% CI 100\%-100\%), respectively. The overall sensitivity and specificity of the antibody and antigen combo test were $86 \%$ (95\% CI 79\%-99\%) and 99\% (95\% CI: 98\%-100\%).

\section{GRADE approach (Grading of Recommendations, Assessment, Development and Evaluation to assessing overall quality of evidence GRADE for RDT versus EIA}

$\mathrm{HCV}$ Ab RDTs showed comparable sensitivity and specificity compared to that of EIAs. Among the five studies that evaluated RDTs versus EIA, 15,943 of samples were evaluated, and moderate risk of bias was observed (Table 4), but there was a consistent high level of specificity. Since the unit of the analysis varied among studies (Table 4), indirectness was 


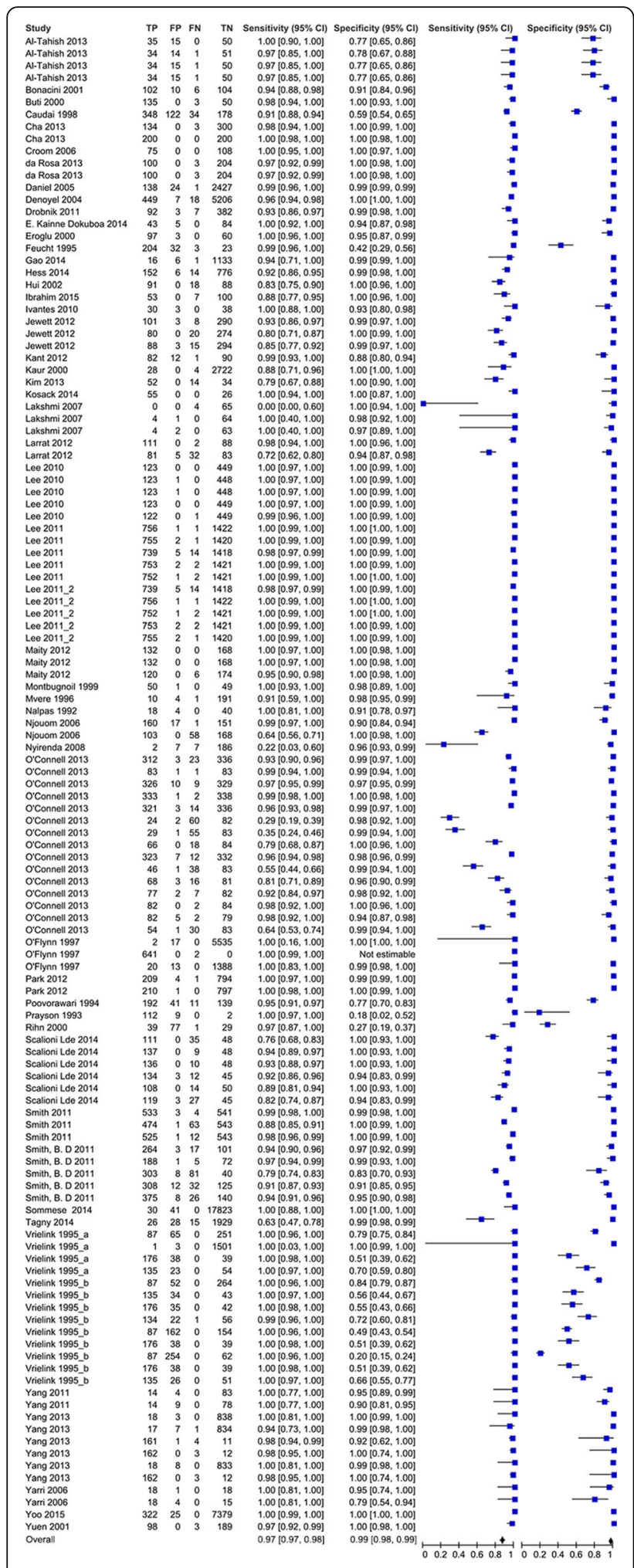

Fig. 2 Sensitivity and specificity of HCV Ab tests included in the review $(n=52)$ observed. In addition, the overall strength of the pooled evaluation was moderate, with pooled sensitivity and specificity of 99\% (95\% CI 98\%-100\%) and $100 \%$ (95\% CI 100\%-100\%), respectively. Under the pre-test probability of $5 \%$, the post-test probability after a positive test result is $97 \%$, and the post-test probability after a negative test result is $100 \%$.

\section{GRADE for oral RDT versus blood reference}

The use of oral RDTs HCV Ab had comparable sensitivity and specificity compared to blood reference standards (Additional file 7). For the 12 studies evaluated oral RDT versus blood reference, 14,547 samples were evaluated. A moderate risk of bias was observed. Inconsistency was present for sensitivity, as the sensitivities of the included studies varied. But there was a consistent high level of specificity. Since the unit of the analysis varied with each other among the included studies (Table 4), indirectness was observed for included studies. In addition, the overall strength of the pooled evaluation was moderate, with pooled sensitivity and specificity of $94 \%$ (95\% CI 93\%-96\%) and 100\% (95\% CI 100\%-100\%), respectively. Assuming a pre-test probability of $5 \%$, the post-test probability after a positive test result was $94 \%$, and the post-test probability after a negative test result was $100 \%$.

\section{Discussion}

There is a global need to expand $\mathrm{HCV}$ diagnostic testing. In this meta-analysis, we found $\mathrm{HCV} \mathrm{Ab}$ RDTs, including those using oral fluid, showed a high overall sensitivity and specificity compared to laboratory-based EIAs. This extends the literature by including several new studies that were not included in prior reviews, including a sub-analysis that focused on use of RDTs with oral fluid. In addition, the evidence collected from this review was used to inform recommendations in the 2017 WHO guidelines on testing for hepatitis B and C [15]. The evidence for generally high levels of diagnostic accuracy across most brands from this systematic review and metaanalysis supported a strong recommendation for the use of HCV RDTs in WHO testing guidelines [15].

Our data suggest that RDTs can be used for HCV Ab detection in a wide range of clinical settings. For example, for all the included studies, 17 were conducted among general populations, 20 were among high risk populations, and 17 were among hospitalized patients (two studies included two kinds of populations). High HCV Ab RDTs sensitivity and specificity were observed across multiple different populations (including general population, high risk populations, and hospital patients), which is consistent with previous systematic reviews [13, 14, 63]. The use of an EIA to detect $\mathrm{HCV}$ Ab followed 
Table 3 Manufacturers and accuracy of RDTs among included studies

\begin{tabular}{|c|c|c|c|c|c|c|c|c|}
\hline First author & Manufacturer & $\begin{array}{l}\text { Sample } \\
\text { size }\end{array}$ & $\mathrm{TP}$ & $\mathrm{FP}$ & TN & $\mathrm{FN}$ & SE & SP \\
\hline Montbugnoil et al. & Anti-HCV Ab rapid test (1st IRP 75/537 by Thema Ricerca, WHO Geneva) & 100 & 50 & 1 & 49 & 0 & $100 \%$ & $98 \%$ \\
\hline $\begin{array}{l}\text { O'Connell, R. J. } \\
\text { et al. }\end{array}$ & Axiom (Axiom Diagnostics, Burstadt,Germany) & 674 & 326 & 10 & 329 & 9 & $97 \%$ & $97 \%$ \\
\hline $\begin{array}{l}\text { O'Connell, R. J. } \\
\text { et al. }\end{array}$ & Axiom (Axiom Diagnostics, Burstadt,Germany) & 168 & 77 & 2 & 82 & 7 & $92 \%$ & $98 \%$ \\
\hline $\begin{array}{l}\text { O'Connell, R. J. } \\
\text { et al. }\end{array}$ & Axiom (Axiom Diagnostics, Burstadt,Germany) & 168 & 82 & 5 & 79 & 2 & $98 \%$ & $94 \%$ \\
\hline $\begin{array}{l}\text { Scalioni Lde, P } \\
\text { et al. }\end{array}$ & Bioeasy HCV Rapid Test, (Bioeasy Diagnóstica Ltd., Brazil) & 194 & 137 & 0 & 48 & 9 & $94 \%$ & $100 \%$ \\
\hline $\begin{array}{l}\text { Scalioni Lde, P } \\
\text { et al. }\end{array}$ & Bioeasy HCV Rapid Test (Bioeasy Diagnóstica Ltd., Brazil) & 194 & 111 & 0 & 48 & 35 & $76 \%$ & $100 \%$ \\
\hline $\begin{array}{l}\text { Scalioni Lde, P } \\
\text { et al. }\end{array}$ & Bioeasy HCV Rapid Test (Bioeasy Diagnóstica Ltd., Brazil) & 194 & 136 & 0 & 48 & 10 & $93 \%$ & $100 \%$ \\
\hline Jewett, A et al. & Chembio DPP HCV Test (Chembio Diagnostic Systems, USA) & 407 & 101 & 3 & 290 & 8 & $93 \%$ & $99 \%$ \\
\hline Jewett, A et al. & Chembio DPP HCV test (Chembio Diagnostic Systems,USA) & 400 & 88 & 3 & 294 & 15 & $85 \%$ & $99 \%$ \\
\hline Smith, B. D et al. & Chembio DPP HCV test (Chembio Diagnostic Systems, USA) & 476 & 308 & 12 & 125 & 32 & $91 \%$ & $91 \%$ \\
\hline Smith, B. D et al. & Chembio DPP HCV test (Chembio Diagnostic Systems, USA) & 385 & 264 & 3 & 101 & 17 & $94 \%$ & $97 \%$ \\
\hline Smith et al. et al. & Chembio DPP HCV test (Chembio Diagnostic Systems, USA) & 1081 & 525 & 1 & 543 & 12 & $98 \%$ & $100 \%$ \\
\hline $\begin{array}{l}\text { O'Connell, R. J. } \\
\text { et al. }\end{array}$ & CORE (CORE Diagnostics, United Kingdom) & 168 & 29 & 1 & 83 & 55 & $35 \%$ & $99 \%$ \\
\hline $\begin{array}{l}\text { O'Connell, R. J } \\
\text { et al. }\end{array}$ & CORE (CORE Diagnostics, United Kingdom) & 168 & 24 & 2 & 82 & 60 & $29 \%$ & $98 \%$ \\
\hline $\begin{array}{l}\text { O'Connell, R. J } \\
\text { et al. }\end{array}$ & CORE (CORE Diagnostics, United Kingdom) & 674 & 323 & 7 & 332 & 12 & $96 \%$ & $98 \%$ \\
\hline Maity et al. & Diagnostics Ltd. (other information is not available) & 300 & 132 & 0 & 168 & 0 & $100 \%$ & $100 \%$ \\
\hline $\begin{array}{l}\text { O'Connell, R. J. } \\
\text { et al. }\end{array}$ & FirstVue (AT First Diagnostic, Woodbury,NY, USA) & 168 & 66 & 0 & 84 & 18 & $79 \%$ & $100 \%$ \\
\hline $\begin{array}{l}\text { O'Connell, R. J. } \\
\text { et al. }\end{array}$ & FirstVue (AT First Diagnostic, Woodbury,NY, USA) & 168 & 54 & 1 & 83 & 30 & $64 \%$ & $99 \%$ \\
\hline $\begin{array}{l}\text { O'Connell, R. J. } \\
\text { et al. }\end{array}$ & FirstVue (AT First Diagnostic, Woodbury,NY, USA) & 674 & 312 & 3 & 336 & 23 & $93 \%$ & $99 \%$ \\
\hline Al-Tahish et al. & Fourth-generation HCV TRI_DOT (J. Mitra Co, India) & 100 & 34 & 15 & 50 & 1 & $97 \%$ & $77 \%$ \\
\hline Daniel et al. & Fourth-generation HCV TRI_DOT (J. Mitra Co, India) & 2590 & 138 & 24 & 2427 & 1 & $99 \%$ & $99 \%$ \\
\hline Kim, M. H. et al. & GENEDIA ${ }^{\oplus}$ HCV Rapid LF (Green Cross medical science corp., Korea) & 100 & 52 & 0 & 34 & 14 & $79 \%$ & $100 \%$ \\
\hline Kaur et al. & HCV Bidot (J. Mitra Co., India) & 2754 & 28 & 0 & 2722 & 4 & $88 \%$ & $100 \%$ \\
\hline Al-Tahish & HCV one step test device (ACON Laboratories, USA) & 100 & 34 & 15 & 50 & 1 & $97 \%$ & $77 \%$ \\
\hline Ivantes et al. & HCV Rapid Test Bioeasy (Bioeasy Diagnostica Ltd., Brazil) & 71 & 30 & 3 & 38 & 0 & $100 \%$ & $93 \%$ \\
\hline da Rosa et al. & HCV Rapid Test Bioeasy ${ }^{\circledast}$ (Standard Diagnostics, South Korea) & 307 & 100 & 0 & 204 & 3 & $97 \%$ & $100 \%$ \\
\hline Poovoran et al. & HCV-SPOT assay (Genelabs Diagnostics Pty Ltd., Singapore) & 192 & 41 & 11 & 139 & 1 & $98 \%$ & $93 \%$ \\
\hline Mvere et al. & HCV-SPOT assay (Genelabs Diagnostics Pty Ltd., Singapore) & 206 & 10 & 4 & 191 & 1 & $91 \%$ & $98 \%$ \\
\hline Njouom et al. & Hexagon ${ }^{\circledast}$ HCV (Not reported manufacturer located country) & 329 & 160 & 17 & 151 & 1 & $99 \%$ & $90 \%$ \\
\hline Al-Tahish et al. & ImmunoComb II HCV (Inverness Medical Innovations, USA) & 100 & 34 & 14 & 51 & 1 & $97 \%$ & $78 \%$ \\
\hline Yarri et al. & ImmunoComb II HCV (Inverness Medical Innovations, USA) & 37 & 18 & 4 & 15 & 0 & $100 \%$ & $79 \%$ \\
\hline Yarri et al. & ImmunoComb II HCV (Inverness Medical Innovations, USA) & 37 & 18 & 1 & 18 & 0 & $100 \%$ & $95 \%$ \\
\hline Njouom et al. & $\begin{array}{l}\text { ImmunoComb }{ }^{\oplus} \text { |I HCV assay (Orgenics Ltd., not reported manufacturer located } \\
\text { country) }\end{array}$ & 329 & 103 & 0 & 168 & 58 & $64 \%$ & $100 \%$ \\
\hline \multirow[t]{2}{*}{ da Rosa et al. } & Imuno-Rapido HCV ${ }^{\circledR}$ (Wama Diagnostica, Brazil). & 307 & 100 & 0 & 204 & 3 & $97 \%$ & $100 \%$ \\
\hline & Instant View Cassette (Alfa Scientific Designs, Poway, CA, USA) & 674 & 321 & 3 & 336 & 14 & $96 \%$ & $99 \%$ \\
\hline
\end{tabular}


Table 3 Manufacturers and accuracy of RDTs among included studies (Continued)

\begin{tabular}{|c|c|c|c|c|c|c|c|c|}
\hline First author & Manufacturer & $\begin{array}{l}\text { Sample } \\
\text { size }\end{array}$ & $\mathrm{TP}$ & $\mathrm{FP}$ & TN & $\mathrm{FN}$ & SE & SP \\
\hline \multicolumn{9}{|l|}{$\begin{array}{l}\text { O'Connell, R. J. } \\
\text { et al. }\end{array}$} \\
\hline $\begin{array}{l}\text { O'Connell, R. J. } \\
\text { et al. }\end{array}$ & Instant View Cassette (Alfa Scientific Designs, Poway, CA, USA) & 168 & 68 & 3 & 81 & 16 & $81 \%$ & $96 \%$ \\
\hline $\begin{array}{l}\text { O'Connell, R. J. } \\
\text { et al. }\end{array}$ & Instant View Cassette (Alfa Scientific Designs, Poway, CA, USA) & 168 & 46 & 1 & 83 & 38 & $55 \%$ & $99 \%$ \\
\hline Maity et al. & J Mitra Co. India other information is not available) & 300 & 120 & 0 & 174 & 6 & $95 \%$ & $100 \%$ \\
\hline Jewett, A et al. & Rapid HIV/HCV antibody test (Medmira Laboratories, Canada) & 374 & 80 & 0 & 274 & 20 & $80 \%$ & $100 \%$ \\
\hline Nyirenda et al. & Monoelisa HCV Ag/Ab ultra-microplate EIA (Bio-Rad, France) & 202 & 2 & 7 & 186 & 7 & $22 \%$ & $96 \%$ \\
\hline Tagny et al. & Monolisa HCV Ag-Ab Ultra, (BioRad, France) & 1998 & 26 & 28 & 1929 & 15 & $63 \%$ & $99 \%$ \\
\hline Smith et al. & Multiplo Rapid HIV/HCV Antibody Test (MedMira, Canada) & 1081 & 474 & 1 & 543 & 63 & $88 \%$ & $100 \%$ \\
\hline Smith, B. D et al. & Multiplo Rapid HIV/HCV Antibody Test (MedMira, Canada) & 432 & 303 & 8 & 40 & 81 & $79 \%$ & $83 \%$ \\
\hline Cha, Y. J. et al. & OraQuick (OraSure Technologies, PA USA) & 437 & 134 & 0 & 300 & 3 & $98 \%$ & $100 \%$ \\
\hline Cha, Y. J. et al. & Architect (Abbott Laboratories, Abbott Park, IL, USA) & 400 & 200 & 0 & 200 & 0 & $100 \%$ & $100 \%$ \\
\hline Lee, S. R et al. & OraQuick (OraSure Technologies, PA USA) & 2183 & 756 & 1 & 1422 & 1 & $100 \%$ & $100 \%$ \\
\hline Lee, S. R et al. & OraQuick (OraSure Technologies, PA USA) & 2183 & 755 & 2 & 1420 & 1 & $100 \%$ & $100 \%$ \\
\hline Lee, S. R et al. & OraQuick (OraSure Technologies, PA USA) & 2183 & 753 & 2 & 1421 & 2 & $100 \%$ & $100 \%$ \\
\hline Lee, S. R et al. & OraQuick (OraSure Technologies, PA USA) & 2183 & 752 & 1 & 1421 & 2 & $100 \%$ & $100 \%$ \\
\hline Lee, S. R et al. & OraQuick (OraSure Technologies, PA USA) & 2183 & 739 & 5 & 1418 & 14 & $98 \%$ & $100 \%$ \\
\hline $\begin{array}{l}\text { O'Connell, R. J } \\
\text { et al. }\end{array}$ & OraQuick (OraSure Technologies, PA USA) & 674 & 333 & 1 & 338 & 2 & $99 \%$ & $100 \%$ \\
\hline $\begin{array}{l}\text { O'Connell, R. J } \\
\text { et al. }\end{array}$ & OraQuick (OraSure Technologies, PA USA) & 168 & 83 & 1 & 83 & 1 & $99 \%$ & $99 \%$ \\
\hline $\begin{array}{l}\text { O'Connell, R. J } \\
\text { et al. }\end{array}$ & OraQuick (OraSure Technologies, PA USA) & 168 & 82 & 0 & 84 & 2 & $98 \%$ & $100 \%$ \\
\hline Smith, B. D et al. & OraQuick (OraSure Technologies, PA USA) & 549 & 375 & 8 & 140 & 26 & $94 \%$ & $.95 \%$ \\
\hline Smith, B. D et al. & OraQuick (OraSure Technologies, PA USA) & 266 & 188 & 1 & 72 & 5 & $97 \%$ & $99 \%$ \\
\hline Lee et al. & OraQuick (OraSure Technologies, PA USA) & 572 & 122 & 0 & 449 & 1 & $99 \%$ & $100 \%$ \\
\hline Lee et al. & OraQuick (OraSure Technologies, PA USA) & 572 & 123 & 0 & 449 & 0 & $100 \%$ & $100 \%$ \\
\hline Lee et al. & OraQuick (OraSure Technologies, PA USA) & 572 & 123 & 0 & 449 & 0 & $100 \%$ & $100 \%$ \\
\hline Lee et al. & OraQuick (OraSure Technologies, PA USA) & 572 & 123 & 1 & 448 & 0 & $100 \%$ & $100 \%$ \\
\hline Lee et al. & OraQuick (OraSure Technologies, PA USA) & 572 & 123 & 1 & 448 & 0 & $100 \%$ & $100 \%$ \\
\hline Smith et al. & OraQuick (OraSure Technologies, PA USA) & 1081 & 533 & 3 & 541 & 4 & $99 \%$ & $99 \%$ \\
\hline Drobnik et al. & OraQuick (OraSure Technologies, PA USA) & 484 & 92 & 3 & 382 & 7 & $93 \%$ & $99 \%$ \\
\hline $\begin{array}{l}\text { Stephen R. Lee } \\
\text { et al. }\end{array}$ & OraQuick (OraSure Technologies, PA USA) & 2180 & 756 & 1 & 1422 & 1 & $100 \%$ & $100 \%$ \\
\hline $\begin{array}{l}\text { Stephen R. Lee } \\
\text { et al. }\end{array}$ & OraQuick (OraSure Technologies, PA USA) & 2178 & 755 & 2 & 1420 & 1 & $100 \%$ & $100 \%$ \\
\hline $\begin{array}{l}\text { Stephen R. Lee } \\
\text { et al. }\end{array}$ & OraQuick (OraSure Technologies, PA USA) & 2178 & 753 & 2 & 1421 & 2 & $100 \%$ & $100 \%$ \\
\hline $\begin{array}{l}\text { Stephen R. Lee } \\
\text { et al. }\end{array}$ & OraQuick (OraSure Technologies, PA USA) & 2176 & 752 & 1 & 1421 & 2 & $100 \%$ & $100 \%$ \\
\hline $\begin{array}{l}\text { Stephen R. Lee } \\
\text { et al. }\end{array}$ & OraQuick (OraSure Technologies, PA USA) & 2176 & 739 & 5 & 1418 & 14 & $98 \%$ & $100 \%$ \\
\hline Gao et al. & OraQuick (OraSure Technologies, PA USA) & 1156 & 16 & 6 & 1133 & 1 & $94 \%$ & $99 \%$ \\
\hline Ibrahim & OraQuick (OraSure Technologies, PA USA) & 160 & 53 & 0 & 100 & 7 & $88 \%$ & $100 \%$ \\
\hline Scalioni Lde, & OraQuick (OraSure Technologies, PA USA) & 172 & 108 & 0 & 50 & 14 & $89 \%$ & $100 \%$ \\
\hline
\end{tabular}


Table 3 Manufacturers and accuracy of RDTs among included studies (Continued)

\begin{tabular}{|c|c|c|c|c|c|c|c|c|}
\hline First author & Manufacturer & $\begin{array}{l}\text { Sample } \\
\text { size }\end{array}$ & TP & FP & TN & $\mathrm{FN}$ & SE & SP \\
\hline Hess et al. & DPP HIV-HCV-Syphilis Assay (Chembio Diagnostic Systems, Inc., Medford, NY). & 948 & 152 & 6 & 776 & 14 & $92 \%$ & $99 \%$ \\
\hline Buti et al. & Not available & 188 & 135 & 0 & 50 & 3 & $98 \%$ & $100 \%$ \\
\hline Yuen et al. & SM-HCV Rapid Test (SERO-Med Laborspezialita"ten GmbH, Eichsta "tt, Germany) & 290 & 98 & 0 & 189 & 3 & $97 \%$ & $100 \%$ \\
\hline Maity et al. & SPAN Diagnostics, Indi, other information is not available & 300 & 132 & 0 & 168 & 0 & $100 \%$ & $100 \%$ \\
\hline Kant et al. & Toyo anti-HCV test (Turklab, Izmir, Turkey) & 185 & 82 & 12 & 90 & 1 & $99 \%$ & $88 \%$ \\
\hline Kosack, C. S. et al. & The ImmunoFlow HCV test (Core Diagnostics,United Kingdom) & 82 & 55 & 0 & 26 & 0 & $100 \%$ & $100 \%$ \\
\hline Scalioni Lde et al. & WAMA Imuno-Rápido HCV Kit (WAMA Diagnóstica, Brazil) & 194 & 119 & 3 & 45 & 27 & $82 \%$ & $94 \%$ \\
\hline $\begin{array}{l}\text { Scalioni Lde, P } \\
\text { et al. }\end{array}$ & WAMA Imuno-Rápido HCV Kit (WAMA Diagnóstica, Brazil) & 194 & 134 & 3 & 45 & 12 & $92 \%$ & $94 \%$ \\
\hline Hui et al. & Not reported & 197 & 91 & 0 & 88 & 18 & $83 \%$ & $100 \%$ \\
\hline
\end{tabular}

by NAT to confirm active infection is standard practice for diagnosis of $\mathrm{HCV}$ infection and recommended by the US Centers for Disease Control and Prevention and the WHO $[64,65]$. However, despite these recommendations, HCV Ab EIA assays have not been widely used because of the complexity of laboratory-based assays, long turnaround time, high cost and requirements for specialized apparatus and trained technicians [13]. To overcome these barriers, RDTs for $\mathrm{HCV}$ Ab screening were developed [66]. They obviate the need for multiple follow-up appointments, shorten wait times, and allow for the simplification and decentralization of testing (Additional file 8). However, it is essential for policymakers, government officials, and health care practitioners engaged in $\mathrm{HCV}$ screening, care, and treatment to be aware that the performance of individual RDTs for detection of HCV Ab vary widely. Individual diagnostic accuracy for specific brands should be examined to ensure acceptable performance.

Our data suggest that oral fluid RDTs have high sensitivity and specificity. This is consistent with other literature [67]. Tests that can be used with non-invasive samples allow testing to be decentralized further and can be used in outreach settings [68]. Our data suggest that oral tests have a slightly lower pooled sensitivity (94\%, 95\%CI: 93\%-96\%) compared to blood-based tests (98\%, 95\% CI: 97\%-98\%) but comparable specificity. Oral HCV Ab RDTs tests may be particularly useful in contexts where venepuncture may be difficult, such as subsets of people who inject drugs which have difficult veins to access.

With the increasing availability of DAAs, countries are seeking testing kits with high sensitivity and specificity, in order to allow them to scale up HCV Ab screening, especially among at-risk populations. The advantages and disadvantages of EIAs and RDTs are well established [15]. Performance, cost, and accessibility need to be considered. Determining which tests to deploy at which level of the health care system and for what settings require policy makers to consider the different attributes of laboratory-based EIA versus blood-based or oral RDTs. Potential trade-offs include slightly lower accuracy for greater uptake and acceptability of testing, provision of test results, and linkage to care. Each country needs to decide on which trade-offs or compromises are acceptable, based not only on disease prevalence and the health care infrastructure but also on technical, socioeconomic, cultural, behavioral considerations. For example, they need to be clear on whether it is acceptable to buy Test $\mathrm{X}$ which is $10 \%$ less accurate than Test $\mathrm{Y}$ but is considerably cheaper so that many more people can be tested. In addition, although oral RDTs are less accurate than blood-based RDTs, it may be that oral RDTs will be more acceptable for outreach testing and accessing at-risk populations and allow the control programs to identify more $\mathrm{HCV}$ cases. In a low prevalence setting, even a test with $98 \%$ specificity can yield more false positive than true positive results. All these tradeoffs can be modeled to give an estimate of the costeffectiveness and potential impact of different strategies for HCV Ab screening.

Our review also underlines some of the common methodological problems encountered in evaluating diagnostic accuracy. Cross-sectional or case-control designs were used by all 52 included studies, introducing a potential risk of bias. These studies used a broad range of reference standards, which makes the pooled performance data less meaningful. Within the evaluation of diagnostic accuracy, even crosssectional studies in patients with diagnostic uncertainty and direct comparison of test results with an appropriate reference standard can be considered high quality [69]. The majority of the included studies used convenience sampling. In this review, we excluded panel studies because they are not based on clinical settings and our purpose was to generate data that would be relevant in clinical settings as part of detection of $\mathrm{HCV} \mathrm{Ab}$. 


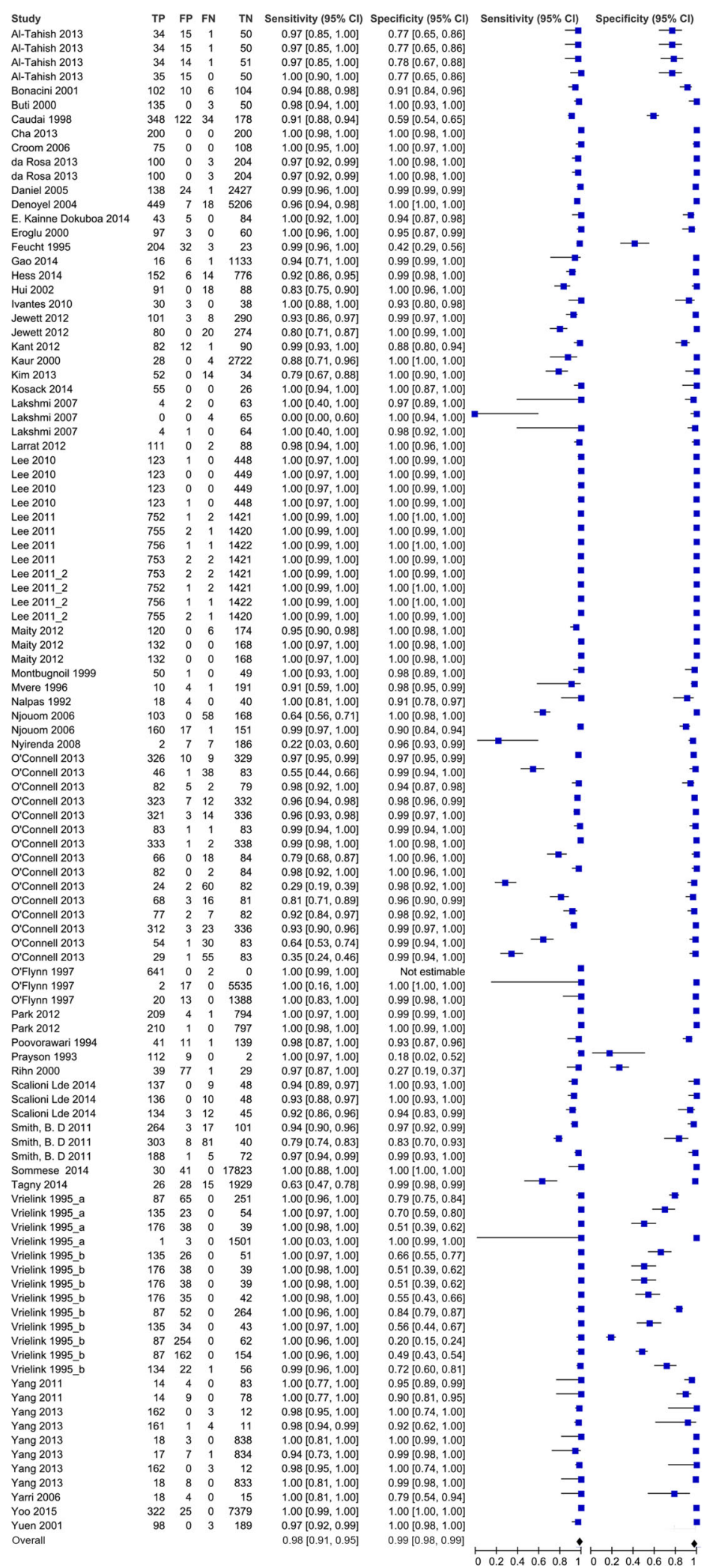

Fig. 3 Pooled HCV Ab test accuracy for blood samples ( $n=47$ studies) 
Table 4 Pooled test accuracy for different testing strategies ( $n=52$ studies)*

\begin{tabular}{|c|c|c|c|c|c|c|c|c|}
\hline \multirow{2}{*}{$\begin{array}{l}\text { Comparison } \\
\text { RDT versus EIA only }(n=5)\end{array}$} & \multirow{2}{*}{$\begin{array}{l}\text { Pooled SE } \\
99 \%\end{array}$} & \multicolumn{2}{|c|}{$95 \% \mathrm{Cl}$} & \multirow{2}{*}{$\begin{array}{l}\text { Tau-square } P \text {-value } \\
\text { for hetero-geneity } \\
<0.001\end{array}$} & \multirow{2}{*}{$\begin{array}{l}\text { Pooled SP } \\
100 \%\end{array}$} & \multicolumn{2}{|l|}{$95 \% \mathrm{Cl}$} & \multirow{2}{*}{$\begin{array}{l}\text { Tau-square } P \text {-value } \\
\text { for hetero-geneity } \\
<0.001\end{array}$} \\
\hline & & $98 \%$ & $100 \%$ & & & $100 \%$ & $100 \%$ & \\
\hline RDT versus NAT or Immunoblot $(n=13)$ & $93 \%$ & $91 \%$ & $95 \%$ & $<0.001$ & $98 \%$ & $97 \%$ & $99 \%$ & $<0.001$ \\
\hline RDT versus EIA, NAT or Immunoblot $(n=14)$ & $97 \%$ & $96 \%$ & $098 \%$ & $<0.001$ & $100 \%$ & $100 \%$ & $100 \%$ & $<0.001$ \\
\hline Oral RDT versus blood reference $(n=12)$ & $94 \%$ & $93 \%$ & $96 \%$ & $<0.001$ & $100 \%$ & $100 \%$ & $100 \%$ & $<0.001$ \\
\hline \multicolumn{9}{|l|}{ Sample type } \\
\hline Blood samples $(n=45)$ & $98 \%$ & $97 \%$ & $98 \%$ & $<0.001$ & $98 \%$ & $98 \%$ & $99 \%$ & \\
\hline Oral samples $(n=12)$ & $94 \%$ & $93 \%$ & $96 \%$ & $<0.001$ & $100 \%$ & $100 \%$ & $100 \%$ & $<0.001$ \\
\hline \multicolumn{9}{|l|}{ Source population } \\
\hline General screening $(n=17)$ & $95 \%$ & $94 \%$ & $96 \%$ & $<0.001$ & $99 \%$ & $98 \%$ & $99 \%$ & $<0.001$ \\
\hline High risk population $(n=19)$ & $97 \%$ & $96 \%$ & $98 \%$ & $<0.001$ & $94 \%$ & $94 \%$ & $95 \%$ & $<0.001$ \\
\hline Hospital patients $(n=16)$ & $97 \%$ & $96 \%$ & $98 \%$ & $<0.001$ & $100 \%$ & $100 \%$ & $100 \%$ & $<0.001$ \\
\hline Antibody and Antigen Combo testing $(n=6)$ & $86 \%$ & $79 \%$ & $94 \%$ & $<0.001$ & $99 \%$ & $98 \%$ & $100 \%$ & $<0.001$ \\
\hline Oral kits brand & & & & & & & $100 \%$ & \\
\hline OraQuick $(n=8)$ & $98 \%$ & $97 \%$ & $99 \%$ & $<0.001$ & $100 \%$ & $100 \%$ & $100 \%$ & $<0.001$ \\
\hline Other brands $(n=6)$ & $88 \%$ & $84 \%$ & $92 \%$ & $<0.001$ & $99 \%$ & $99 \%$ & $100 \%$ & $<0.001$ \\
\hline
\end{tabular}

Notes: *Studies conducted in both LMIC and high-income countries were not included here

Studies conducted cross these regions were not included here

SE sensitivity, SP specificity

Most studies that reported HIV or HBV co-infection only reported the test performance of the kits among all samples, instead of disaggregated diagnostic accuracy. There were insufficient data from two studies to undertake a subanalysis based on HIV co-infection. It may be important for policymakers to know the diagnostic accuracy of $\mathrm{HCV} \mathrm{Ab}$ tests among individuals with coinfections, particularly HIV co-infection [70], and this requires further research among co-infected individuals.

Our study is subject to several limitations. First, we included studies conducted among the general population, hospital patients, and high risk populations. Diagnostic performance can be influenced by disease prevalence and $\mathrm{HCV}$ prevalence is variable among these different populations [71, 72]. Second, we detected substantial heterogeneity that could influence our confidence in the review findings [73], but addressed this problem through a series of sub-group stratified analyses. Third, about 20 brands of RDT kits were used in the included studies, and their performance varies considerably. This limited our ability to summarize the accuracy of different brands, with the exception of comparing OraQuick to other brands. Another concern is publication bias, as studies with poor test performance may be less likely to be published, leading to distorted estimates of accuracy [74]. Fourth, since not all HCV RDTs can be performed from oral fluid/capillary whole blood (some require plasma/serum), and some of them require a cold chain for storage and transport, the direct comparison between EIA and RDTs in this metaanalysis would be less meaningful. Fifth, we should note that not all test kits are still on the market and that versions of the tests included in this metaanalysis may have since changed. Finally, statistical heterogeneity was present. But is common in metaanalyses of diagnostic studies. Additional research is important for understanding why the tests perform more poorly in certain populations or settings.

\section{Conclusion}

RDTs, including oral tests, have excellent sensitivity and specificity compared to laboratory-based methods for $\mathrm{HCV}$ antibody detection across a wide range of settings. National policymakers should consider the performance, cost and accessibility of RDTs into consideration, when selecting assays for use in their national testing algorithms.

\section{Additional files}

Additional file 1: Pooled test accuracy of HCV Ab RDTs compared to an EIA reference (5 studies). (DOCX $360 \mathrm{~kb}$ )

Additional file 2: Pooled test accuracy of HCV Ab RDTs compared to a NAT or immunoblot reference ( $n=13$ studies). (DOCX $621 \mathrm{~kb}$ )

Additional file 3: Pooled test accuracy of HCV Ab RDTs compared to EIA, NAT or immunoblot reference standards ( $n=14$ studies). (DOCX $1170 \mathrm{~kb}$ )

Additional file 4: Pooled test accuracy for oral HCV Ab RDTs compared to blood as a reference ( $n=11$ studies). (DOCX $349 \mathrm{~kb}$ ) 
Additional file 5: Pooled test accuracy for HCV Ab OraQuick kits ( $n=8$ studies). (DOCX $414 \mathrm{~kb}$ )

Additional file 6: Pooled test accuracy for other brands of oral HCV Ab test kits ( $n=6$ studies). (DOCX $406 \mathrm{~kb}$ )

Additional file 7: Grade Table. (DOCX $19 \mathrm{~kb}$ )

Additional file 8: Advantages and Disadvantages of Laboratory based EIAs vs RDTs. (DOCX $14 \mathrm{~kb}$ )

\section{Abbreviations}

Cl: Confidence interval; DAAs: Direct acting antivirals; ElA: Enzyme immunoassay; FN: False negative; FP: False positive; HCV Ab: HCV antibody; HCV: Hepatitis C Virus; NAT: Nucleic acid testing; NPV: Negative predictive value; POC: Point-of-care; PPV: Positive predictive value, RCT: Randomised control trial; RDTs: Rapid diagnostic tests; SE: Sensitivity; SP: Specificity; TN: True negative; TP: True Positive; WHO: World Health Organization

\section{Acknowledgements}

The authors acknowledge the support of WHO, London School of Hygiene \& Tropical Medicine, SESH Global and UNC Project China.

\section{Funding}

This work was supported by the National Institutes of Health National Institute of Allergy and Infectious Diseases 1R01Al114310-01 to JT, UNC-South China STD Research Training Centre Fogarty International Centre 1D43TW009532-01 to JT, and the World Health Organization. Publication of this article was funded by the World Health Organization.

\section{Availability of data and materials}

The dataset supporting the conclusions of this article is included within the article's additional file.

\section{About this supplement}

This article has been published as part of BMC Infectious Diseases Volume 17 Supplement 1, 2017: Testing for chronic hepatitis B and C - a global perspective. The full contents of the supplement are available online at https://bmcinfectdis. biomedcentral.com/articles/supplements/volume-17-supplement-1.

\section{Authors' contributions}

All authors have read and approved the final manuscript. This review was prepared by WT, WC, RP and JDT. AA, DB, OV and JF helped on build searching algorism and performed the literature search. RP and JDT designed the study, and $R P, J D T, A A, D B, O V$ and $P E$ reviewed the manuscript.

\section{Ethics approval and consent to participate}

Not applicable.

\section{Consent for publication}

Not applicable.

\section{Competing interests}

The authors declare that they have no competing interests.

\section{Publisher's Note}

Springer Nature remains neutral with regard to jurisdictional claims in published maps and institutional affiliations.

\footnotetext{
Author details

'University of North Carolina Project-China, No. 2 Lujing Road, Guangzhou 510095, China. ${ }^{2}$ Guangdong Provincial Dermatology Hospital (Dermatology Hospital, Southern Medical University), Guangzhou, China. ${ }^{3} \mathrm{SESH}$ Global, Guangzhou, China. ${ }^{4}$ School of Medicine, University of North Carolina at Chapel Hill, Chapel Hill, NC, USA. ${ }^{5}$ School of Public Health, Sun Yat-sen University, Guangzhou, China. ${ }^{6}$ Center for Migrant Health Policy, Sun Yat-sen University, Guangzhou, China. ${ }^{7}$ London School of Hygiene and Tropical Medicine, Keppel St, London, UK. ${ }^{8}$ Global Hepatitis Programme, HIV Department, World Health Organization, Geneva, Switzerland.
}

Published: 1 November 2017

\section{References}

1. World Health Organization. New recommendations in the updated WHO guidelines for the screening, care and treatment of persons with chronic hepatitis C infection. Geneva: WHO; 2016. http://www.who.int/hepatitis/ publications/hepatitis-c-guidelines-2016/en/.

2. Lavanchy D. The global burden of hepatitis C. Liver Int. 2009;29(s1):74-81.

3. World Health Organization. Global Hepatitis Report, 2017. Geneva; 2017. http://www.who.int/hepatitis/publications/global-hepatitis-report2017/en/. Accessed 6 Oct 2017.

4. Feeney ER, Chung RT. Antiviral treatment of hepatitis C. BMJ (Clinical research ed). 2014;348:93308.

5. Pawlotsky JM. New hepatitis $C$ therapies: the toolbox, strategies, and challenges. Gastroenterology. 2014;146(5):1176-92.

6. Soriano V, Labarga P, Fernández-Montero JV, Benito JM, Poveda E, Rallon N, Sánchez C, Vispo E, Barreiro P. The changing face of hepatitis $C$ in the new era of direct-acting antivirals. Antivir Res. 2013;97(1):36-40.

7. Papatheodoridis G, Tsochatzis E, Hardke S, Wedemeyer H. Barriers to care and treatment for patients with chronic viral hepatitis in europe: a systematic review. Liver Int. 2014;34(10):1452-63.

8. Z Zheng H, Li M, Chi B, Wu XX, Wang J, Liu DW. IL28B rs12980275 variant as a predictor of sustained virologic response to pegylated-interferon and ribavirin in chronic hepatitis C patients: a systematic review and metaanalysis. Clin Res Hepatol Gastroenterol. 2015;35(5):576-83.

9. Manzano-Robleda Mdel C, Ornelas-Arroyo V, Barrientos-Gutierrez T, MendezSanchez N, Uribe M, Chavez-Tapia NC. Boceprevir and telaprevir for chronic genotype 1 hepatitis $C$ virus infection. A systematic review and metaanalysis. Ann Hepatol. 2015;14(1):46-57.

10. Ambrosino P, Lupoli R, Tarantino P, Di Minno A, Tarantino L, Di Minno MN. Viral hepatitis and anti-phospholipid antibodies positivity: a systematic review and meta-analysis. Dig Liver Dis. 2015;47(6):478-87.

11. Khodabandehloo M, Roshani D. Prevalence of hepatitis C virus genotypes in Iranian patients: a systematic review and meta-analysis. Hepat Mon. 2014; 14(12):e22915.

12. Khodabandehloo M, Roshani D, Sayehmiri K. Prevalence and trend of hepatitis $C$ virus infection among blood donors in Iran: a systematic review and meta-analysis. J Res Med Sci. 2013;18(8):674-82.

13. Khuroo MS, Khuroo NS, Khuroo MS. Diagnostic accuracy of point-of-care tests for hepatitis $C$ virus infection: a systematic review and meta-analysis. PLoS One. 2015;10(3):e0121450.

14. Shivkumar S, Peeling R, Jafari Y, Joseph L, Pant Pai N. Accuracy of rapid and point-of-care screening tests for hepatitis $\mathrm{C}$ : a systematic review and metaanalysis. Ann Intern Med. 2012;157(8):558-66.

15. World Health Organization. Guidelines on hepatitis B and C testing. Geneva; 2017. Available: http://www.who.int/hepatitis/publications/guidelineshepatitis-c-b-testing/en/. Accessed 6 Oct 2017.

16. UNAIDS. Unaids terminology guidelines. Geneva: UNADIS; 2015.

17. Whiting PF, Rutjes AW, Westwood ME, Mallett S, Deeks JJ, Reitsma JB, Leeflang MM, Sterne JA, Bossuyt PM, Group Q. QUADAS-2: a revised tool for the quality assessment of diagnostic accuracy studies. Ann Intern Med. 2011;155(8):529-36.

18. Bossuyt PM, Reitsma JB, Bruns DE, Gatsonis CA, Glasziou PP, Irwig LM, Moher D, Rennie D, de Vet HC, Lijmer JG, et al. The STARD statement for reporting studies of diagnostic accuracy: explanation and elaboration. Ann Intern Med. 2003;138(1):W1-12.

19. da Rosa L, Dantas-Correa EB, Narciso-Schiavon JL, Schiavon LL. Diagnostic performance of two point-of-care tests for anti-HCV detection. Hepat Mon. 2013;13(9):e12274.

20. Al-Tahish G, El-Barrawy MA, Hashish MH, Heddaya Z. Effectiveness of three types of rapid tests for the detection of hepatitis $C$ virus antibodies among blood donors in Alexandria, Egypt. J Virol Methods. 2013;189(2):370-4.

21. Buti M, Cotrina M, Chan H, Jardi R, Rodriguez F, Costa X, Esteban R, Guardia J. Rapid method for the detection of anti-HCV antibodies in patients with chronic hepatitis C. Rev Esp Enferm Dig. 2000;92(3):140-6.

22. Cha YJ, Park Q, Kang ES, Yoo BC, Park KU, Kim JW, Hwang YS, Kim MH. Performance evaluation of the OraQuick hepatitis $C$ virus rapid antibody test. Ann Lab Med. 2013;33(3):184-9.

23. Daniel HD, Abraham P, Raghuraman S, Vivekanandan P, Subramaniam T, Sridharan $\mathrm{G}$. Evaluation of a rapid assay as an alternative to conventional enzyme immunoassays for detection of hepatitis $C$ virus-specific antibodies. J Clin Microbiol. 2005;43(4):1977-8. 
24. Drobnik A, Judd C, Banach D, Egger J, Konty K, Rude E. Public health implications of rapid hepatitis $C$ screening with an oral swab for community-based organizations serving high-risk populations. Am J Public Health. 2011;101(11):2151.

25. Hess KL, Fisher DG, Reynolds GL. Sensitivity and specificity of point-of-care rapid combination syphilis-HIV-HCV tests. PLoS One. 2014;9(11):e112190.

26. Hui AY, Chan FK, Chan PK, Tam JS, Sung JJ. Evaluation of anew rapid wholeblood serological test for hepatitis c virus. Acta Virol. 2002;46(1):47-8.

27. Ibrahim S, Al Attas SA, Mansour GA, Ouda S, Fallatah H. Accuracy of rapid oral HCV diagnostic test among a Saudi sample. Clin Oral Investig. 2015;19(2):475-80.

28. Ivantes CA, Silva D, Messias-Reason I. High prevalence of hepatitis C associated with familial history of hepatitis in a small town of south Brazil: efficiency of the rapid test for epidemiological survey. Braz J Infect Dis. 2010;14(5):483-8.

29. Jewett A, Smith BD, Garfein RS, Cuevas-Mota J, Teshale EH, Weinbaum CM. Field-based performance of three pre-market rapid hepatitis $C$ virus antibody assays in STAHR (study to assess hepatitis $C$ risk) among young adults who inject drugs in San Diego, CA. J Clin Virol. 2012;54(3):213-7.

30. Kant J, Moller B, Heyne R, Herber A, Bohm S, Maier M, Liebert UG, Mossner J, Berg T, Wiegand J. Evaluation of a rapid on-site anti-HCV test as a screening tool for hepatitis C virus infection. Eur J Gastroenterol Hepatol. 2013;25(4):416-20.

31. Kaur H, Dhanao J, Oberoi A. Evaluation of rapid kits for detection of HIV, HBsAg and HCV infections. Indian J Med Sci. 2000;54(10):432-4.

32. Kim MH, Kang SY, Lee WI. Evaluation of a new rapid test kit to detect hepatitis C virus infection. J Virol Methods. 2013;193(2):379-82.

33. Lee SR, Kardos K, Yearwood G, Kurtz L, Roehler M, Feiss G. Results of a multi-center evaluation of a new rapid test for detection of HCV infection using whole blood, serum, plasma and oral fluid. J Hepatol. 2010;52:S271.

34. Lee SR, Kardos KW, Schiff E, Berne CA, Mounzer K, Banks AT, Tatum HA, Friel TJ, Demicco MP, Lee WM, et al. Evaluation of a new, rapid test for detecting HCV infection, suitable for use with blood or oral fluid. J Virol Methods. 2011:172(1-2):27-31

35. Lee SR, Yearwood GD, Guillon GB, Kurtz LA, Fischl M, Friel T, Berne CA, Kardos KW. Evaluation of a rapid, point-of-care test device for the diagnosis of hepatitis C infection. J Clin Virol. 2010;48(1):15-7.

36. Maity S, Nandi S, Biswas S, Sadhukhan SK, Saha MK. Performance and diagnostic usefulness of commercially available enzyme linked immunosorbent assay and rapid kits for detection of HIV, HBV and HCV in India. Virol J. 2012;9:290.

37. Montebugnoli L, Borea G, Miniero R, Sprovieri G. A rapid test for the visual detection of anti-hepatitis $C$ virus antibodies in whole blood. Clin Chim Acta. 1999;288(1-2):91-6.

38. Mvere D, Constantine NT, Katsawde E, Tobaiwa O, Dambire S, Corcoran P. Rapid and simple hepatitis assays: encouraging results from a blood donor population in Zimbabwe. Bull World Health Organ. 1996;74(1):19-24.

39. Njouom R, Tejiokem MC, Zanga MC, Pouillot R, Ayouba A, Pasquier C, Nerrienet E. A cost-effective algorithm for the diagnosis of hepatitis $C$ virus infection and prediction of HCV viremia in Cameroon. J Virol Methods. 2006; 133(2):223-6.

40. Nyirenda M, Beadsworth MB, Stephany P, Hart CA, Hart IJ, Munthali C, Beeching $\mathrm{N}$, Zijlstra EE. Prevalence of infection with hepatitis B and C virus and coinfection with HIV in medical inpatients in Malawi. J Infect. 2008;57(1):72-7.

41. O'Connell RJ, Gates RG, Bautista CT, Imbach M, Eggleston JC, Beardsley SG, Manak MM, Gonzales R, Rentas FJ, Macdonald WW, et al. Laboratory evaluation of rapid test kits to detect hepatitis $\mathrm{C}$ antibody for use in predonation screening in emergency settings. Transfusion. 2013;53(3):505-17.

42. Poovorawan $Y$, Theamboonlers A, Chumdermpadetsuk S, Thong CP. Comparative results in detection of HCV antibodies by using a rapid HCV test, ELISA and immunoblot. Southeast Asian J Trop Med Public Health. 1994;25(4):647-9.

43. Scalioni Lde P, Cruz HM, de Paula VS, Miguel JC, Marques VA, VillelaNogueira CA, Milagres FA, Cruz MS, Bastos Fl, Andrade TM, et al. Performance of rapid hepatitis $C$ virus antibody assays among high- and low-risk populations. J Clin Virol. 2014;60(3):200-5.

44. Smith BD, Drobeniuc J, Jewett A, Branson BM, Garfein RS, Teshale E, Kamili $S$, Weinbaum CM. Evaluation of three rapid screening assays for detection of antibodies to hepatitis C virus. J Infect Dis. 2011;204(6):825-31.

45. Smith $B D$, Teshale $E$, Jewett $A$, Weinbaum $C M$, Neaigus $A$, Hagan $H$, Jenness SM, Melville SK, Burt R, Thiede $H$, et al. Performance of premarket rapid hepatitis $C$ virus antibody assays in 4 national human immunodeficiency virus behavioral surveillance system sites. Clin Infect Dis. 2011;53(8):780-6.
46. Tagny CT, Mbanya D, Murphy EL, Lefrere JJ, Laperche S. Screening for hepatitis $\mathrm{C}$ virus infection in a high prevalence country by an antigen/antibody combination assay versus a rapid test. J Virol Methods. 2014;199:119-23.

47. Yaari A, Tovbin D, Zlotnick M, Mostoslavsky M, Shemer-Avni Y, Hanuka N, Burbea Z, Katzir Z, Storch S, Margalith M. Detection of HCV salivary antibodies by a simple and rapid test. J Virol Methods. 2006;133(1):1-5.

48. Yuen MF, Hui CK, Yuen JC, Young JL, Lai CL. The accuracy of SM-HCV rapid test for the detection of antibody to hepatitis C virus. Am J Gastroenterol. 2001;96(3):838-41.

49. Gao F, Talbot EA, Loring CH, Power JJ, Dionne-Odom J, Alroy-Preis $\mathrm{S}$, Jackson P, Bean CL. Performance of the OraQuick HCV rapid antibody test for screening exposed patients in a hepatitis $\mathrm{C}$ outbreak investigation. J Clin Microbiol. 2014;52(7):2650-2.

50. Kosack CS, Nick S, Shanks L. Diagnostic accuracy evaluation of the ImmunoFlow HCV rapid immunochromatographic test for the detection of hepatitis C antibodies. J Virol Methods. 2014;204:6-10.

51. Lee SR, Kardos K, Yearwood G, Kurtz L, Roehler M, Feiss G. Results of a multi-center evaluation of a new rapid test for detection of HCV infection using whole blood, serum, plasma and oral fluid. J Hepatol. 2011;52:S271.

52. Larrat S, Bourdon C, Baccard M, Garnaud C, Mathieu S, Quesada JL, SignoriSchmuck A, Germi R, Blanc M, Leclerca P, et al. Performance of an antigenantibody combined assay for hepatitis $\mathrm{C}$ virus testing without venipuncture. J Clin Virol. 2012;55(3):220-5.

53. Nalpas B, Thiers V, Pol S, Driss F, Thepot V, Berthelot P, Brechot C. Hepatitis-C Viremia and anti-Hcv antibodies in alcoholics. J Hepatol. 1992;14(2-3):381-4.

54. Prayson RA, Proffitt MR, Sharp DE, Carey WD. Application of a 2ndgeneration recombinant Immunoblot assay to assess hepatitis-C infection. Lab Med. 1993;24(11):732-8.

55. Feucht HH, Zollner B, Polywka S, Laufs R. Study on reliability of commercially available hepatitis C virus antibody tests. J Clin Microbiol. 1995;33(3):620-4.

56. Vrielink H, Zaaijer HL, Reesink HW, van der Poel CL, Cuypers HT, Lelie PN Sensitivity and specificity of three third-generation anti-hepatitis $C$ virus ELISAs. Vox Sang. 1995;69(1):14-7.

57. O'Flynn N, Jilg W, McQuillan T, Bauer I, Heyermann M, Schulte-Kellinghaus B, Moller D. New HCV assay on the Abbott AxSYM random access analyzer. Clin Lab. 1997;43(5):403-9.

58. Caudai C, Padula MG, Bastianoni I, Valensin PE, Shyamala V, Han J, Boggiano CA, Almi P. Antibody testing and RT-PCR results in hepatitis $\mathrm{C}$ virus (HCV) infection: HCV-RNA detection in PBMC of plasma viremia-negative HCVSeropositive persons. Infection. 1998;26(3):151-4.

59. Bonacini $M$, Lin HJ, Hollinger FB. Effect of coexisting HIV-1 infection on the diagnosis and evaluation of hepatitis C virus. J Acquir Immune Defic Syndr. 2001;26(4):340-4.

60. Yang JF, Lin YY, Hsieh MH, Tsai CH, Liu SF, Yu ML, Dai CY, Huang JF, Lin WY, $L$ in $Z Y$, et al. Performance characteristics of a combined hepatitis $C$ virus core antigen and anti-hepatitis $C$ virus antibody test in different patient groups. Kaohsiung J Med Sci. 2011;27(7):258-63.

61. Yang R, Guan W, Wang Q, Liu Y, Wei L. Performance evaluation and comparison of the newly developed Elecsys anti-HCV II assay with other widely used assays. Clin Chim Acta. 2013;426:95-101.

62. Yoo SJ, Wang LL, Ning HC, Tao CM, Hirankarn N, Kuakarn S, Yang R, Han TH, Chan RC, Hussain BM, et al. Evaluation of the Elecsys anti-HCV II assay for routine hepatitis C virus screening of different Asian Pacific populations and detection of early infection. J Clin Virol. 2015;64:20-7.

63. Aspinall EJ, Doyle JS, Corson S, Hellard ME, Hunt D, Goldberg D, Nguyen T, Falck-Ytter Y, Morgan RL, Smith B, Stoove M, Wiktor SZ, Hutchinson S. Targeted hepatitis $\mathrm{C}$ antibody testing interventions: a systematic review and meta-analysis. Eur J Epidemiol. 2015;30(2):115-29.

64. Alter MJ, Kuhnert WL, Finelli L Centers for Disease Control and Prevention. Guidelines for laboratory testing and result reporting of antibody to hepatitis C virus. Centers for Disease Control and Prevention. MMWR Recomm Rep. 2003;52:1-13, 15.

65. World Health Organization. Guidelines for the screening, care, and treatment of persons with hepatitis C infection. Geneva; 2014. Available: http://www.who. int/hiv/pub/hepatitis/hepatitis-c-guidelines/en/. Accessed 6 Oct 2017.

66. St John A, Price CP. Economic evidence and point-of-care testing. Clin Biochem Rev. 2013;34(2):61.

67. D'Angelo RG, Klepser M, Woodfield R, Patel H. Hepatitis C virus screening a review of the OraQuick hepatitis $C$ virus rapid antibody test. J Pharm Technol. 2015;31(1):13-9. 
68. Parisi MR, Soldini L, Vidoni G, Mabellini C, Belloni T, Brignolo L, Negri S, Schlusnus K, Dorigatti F, Lazzarin A. Point-of-care testing for HCV infection: recent advances and implications for alternative screening. New Microbiol. 2014;37(4):449-547.

69. Schünemann HJ, Oxman AD, Brozek J, Glasziou P, Jaeschke R, Vist GE,

Williams JW Jr, Kunz R, Craig J, Montori VM. Grading quality of evidence and strength of recommendations for diagnostic tests and strategies. BMJ (Clinical research ed). 2008;336(7653):1106-10.

70. Operskalski EA, Kovacs A. HIV/HCV Co-infection: Pathogenesis, Clinical Complications, Treatment, and New Therapeutic Technologies. Curr HIV/ AIDS Rep. 2011;8:12.

71. Shepard CW, Finelli L, Alter MJ. Global epidemiology of hepatitis C virus infection. Lancet Infect Dis. 2005;5(9):558-67.

72. Leeflang MM, Moons KG, Reitsma JB, Zwinderman AH. Bias in sensitivity and specificity caused by data-driven selection of optimal cutoff values: mechanisms, magnitude, and solutions. Clin Chem. 2008:54(4):729-37.

73. Irwig L, Macaskill P, Glasziou P, Fahey M. Meta-analytic methods for diagnostic test accuracy. J Clin Epidemiol. 1995;48(1):119-30.

74. Rothstein HR, Sutton AJ, Borenstein M. Publication bias in meta-analysis: Prevention, assessment and adjustments. John Wiley \& Sons; 2006.

\section{Submit your next manuscript to BioMed Central} and we will help you at every step:

- We accept pre-submission inquiries

- Our selector tool helps you to find the most relevant journal

- We provide round the clock customer support

- Convenient online submission

- Thorough peer review

- Inclusion in PubMed and all major indexing services

- Maximum visibility for your research

Submit your manuscript at www.biomedcentral.com/submit 